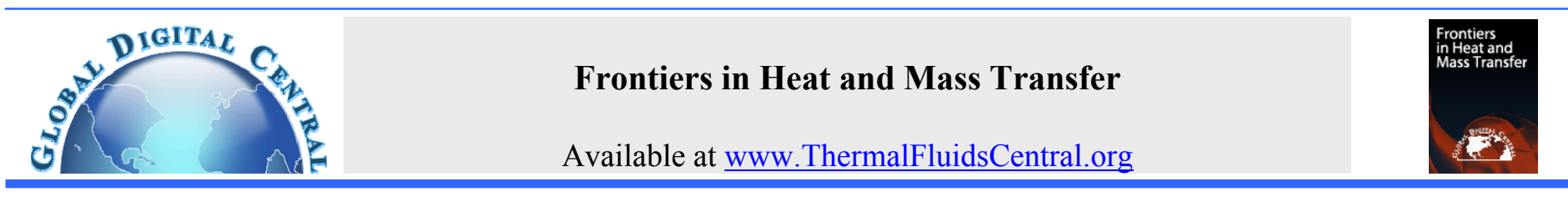

\title{
ADVANCED SPREADERS FOR ENHANCED COOLING OF HIGH POWER CHIPS
}

\author{
Mohamed S. El-Genk ${ }^{\mathrm{a}, \mathrm{b}, \mathrm{c}, *}$, Amir F. Ali ${ }^{\mathrm{a}, \mathrm{c}}$ \\ ${ }^{\mathrm{a}}$ Institute for Space and Nuclear Power Studies, ${ }^{\mathrm{b}} \mathrm{Chemical}$ and Nuclear Engineering Department, \\ ${ }^{c}$ Mechanical Engineering Department, University of New Mexico, Albuquerque, NM, 87131, USA
}

\begin{abstract}
Advanced spreaders for cooling a $10 \times 10 \mathrm{~mm}$ underlying computer chip with a central hot spot (CHS) could remove $>85 \mathrm{~W}$ of dissipated thermal power at junctions' temperature $<100^{\circ} \mathrm{C}$. The spreaders comprise a $1.6-3.2 \mathrm{~mm}$ thick $\mathrm{Cu}$ substrate and an $80-\mu \mathrm{m}$ thick micro-porous copper (MPC) surface cooled by saturation nucleate boiling of PF-5060 dielectric liquid. Investigated are the effects of varying the heat flux at the chip's 1 and 4 $\mathrm{mm}^{2} \mathrm{CHS}$ and the impedance of thermal interface material (TIM) between the $\mathrm{Cu}$ substrate and underlying chip. Results confirmed the effectiveness of the MPC spreaders for cooling the chip and mitigating the effect of CHSs. With a TIM impedance of $0.19^{\circ} \mathrm{C}-\mathrm{cm}^{2} / \mathrm{W}$, the MPC spreader with a 3.2 mm-thick $\mathrm{Cu}$ substrate removes $90.1 \mathrm{~W}$ and $87.85 \mathrm{~W}$ for the chip with 1 and $4 \mathrm{~mm}^{2} \mathrm{CHS}$ when the heat flux ratio (HFR) at CHSs $=6$. The chip maximum surface temperatures at the CHSs are $90.16^{\circ} \mathrm{C}$ and $96.6^{\circ} \mathrm{C}$ and the spreader's footprint areas are 25.5 and $25.25 \mathrm{~cm}^{2}$, respectively. Decreasing the TIM impedance to $0.02^{\circ} \mathrm{C}-\mathrm{cm}^{2} / \mathrm{W}$ decreases the chip's maximum surface temperatures to 73.4 and $76.1^{\circ} \mathrm{C}$, but slightly changes the removed thermal powers from the MPC surface to $90.3 \mathrm{~W}$ and $86.24 \mathrm{~W}$, respectively.
\end{abstract}

Keywords: Immersion cooling nucleate boiling; dielectric liquids; central hot spot; micro-porous copper; thermal interface material; footprint area.

\section{INTRODUCTION}

The continuing increases in the transistors density and modulation frequency for high power computer chips develop surface hot spots, at which the local heat flux could be as much as $1000 \mathrm{~W} / \mathrm{cm}^{2}$. The resulting high surface temperatures at the hot spots induce structural stresses, compromising the chip's service life and increasing its failure frequency. Thus, is it desirable to increase the removal rate of the thermal power dissipated by the chip and mitigate the effect of the surface hot spots, while maintaining acceptable junctions' temperature $\left(\leq 85-125^{\circ} \mathrm{C}\right.$ depending on the application, ITRS (2009)).

Nucleate boiling of dielectric liquids, such as FC-72, HFE-7100 and PF-5060, has been the subject of many investigations for potential application to immersion cooling of high power chips, Anderson and Mudawar (1989); Liu et al. (2001); Honda and Wei (2003); Lin and Banerjee (2008); El-Genk et al. (2007); El-Genk and Saber (2008); ElGenk (2012); Rainey and You (2000); Chang and You (1997). Besides their relatively low saturation temperatures $\left(54-61^{\circ} \mathrm{C}\right.$ at atmospheric pressure), these liquids are chemically inert, environmentally friendly and compatible with many structural materials of interest. These highly wetting liquids, however, cause an excursion in surface temperature prior to nucleate boiling incipience, El-Genk and Bostanci (2003); Jung and Kwak (2006); Parker and El-Genk (2005); Reed and Mudawar (1997). Such an excursion is undesirable because they could markedly increase the junctions' temperature of the chip.

Porous, micro-porous, macro-structured, and macro- and microfinned surfaces and surfaces with micro-porous coatings have been shown to enhance nucleate boiling of dielectric liquids, Reed and Mudawar (1997), Chang and You (1997); Launay et al. (2006); Liu et al. (2001); El-Genk and Parker (2005); Ferjančič et al. (2006); El-Genk and Ali (2010). The measured enhancements in the nucleate boiling heat transfer coefficient on these surfaces, compared to plane $\mathrm{Cu}$, have been attributed to increases in the surface density of active sites for bubbles nucleation. Some of these surfaces have been shown to either eliminate or markedly reduce the excursion in surface temperature prior to nucleate boiling incipience.

Recent experiments by the authors investigated nucleate boiling of PF-5060 dielectric liquid on micro-porous copper (MPC) surfaces of different thicknesses $(80-197 \mu \mathrm{m})$. These surfaces are deposited using electrochemical processes on $10 \times 10 \mathrm{~mm}$ and $1.68 \mathrm{~mm}$-thick $\mathrm{Cu}$ substrates, El-Genk and Ali (2010); Shin and Liu (2004); Shin et al. (2003). Pool boiling experiments using these MPC surfaces demonstrated significant enhancements in the saturation nucleate boiling heat transfer coefficient for PF-5060 dielectric liquid, and either a decrease $\left(\leq 15^{\circ} \mathrm{C}\right)$ (Fig.2) or elimination of temperature excursions.

Figure 1 presents Scanning Electron Microscope (SEM) images of the $80-\mu \mathrm{m}$ thick MPC surface, El-Genk and Ali (2010). They show patterned round and shallow depressions surrounded by dense structure of $\mathrm{Cu}$ micro-particles and clusters, ranging in sizes from a faction of a micron to a few microns. The $\mathrm{Cu}$ micro-particles and clusters are also present on the inside of the round depressions. These depressions increase the effective wetted surface area for nucleate boiling and the porous copper micro-structure increases the density of the active sites for bubbles nucleation. The combined contribution enhances nucleate boiling heat transfer on the MPC surfaces, El-Genk and Ali (2010).

Recent numerical analysis performed to investigate the application of nucleate boiling of PF-5060 dielectric liquid on MPC surfaces to immersion cooling of high power computer chips using MPC spreaders. The spreaders comprise a $\mathrm{Cu}$ substrate $(1.6-3.2 \mathrm{~mm}$ thick $)$ and $80-\mu \mathrm{m}$ thick MPC surface layer, Ali and El-Genk (2012a and 2012b), cooled by saturation nucleate boiling of PF-5060 dielectric liquid. The MPC

*Corresponding author: Regents’ Professor and Director, Institute for Space and Nuclear Power Studies, (505) 277-5542, E-mail: mgenk@unm.edu. 
spreaders take advantage of the nucleate boiling enhancement on the MPC surface and the good heat spreading through the $\mathrm{Cu}$ substrates. The numerical analysis of Ali and El-Genk (2012a and 2012b) did not directly incorporate the effect of the TIM resistance between the $\mathrm{Cu}$ substrate and the underling chip, but used the values of the measured experimental values of the nucleate boiling heat transfer coefficient, $\mathrm{h}_{\mathrm{NB}}$, for PF-5060 liquid on 80- $\mu \mathrm{m}$ thick MPC (Fig. 2), El-Genk and Ali (2010). The pool boiling experiments are performed by controlling and incrementally increasing the input power and recording the surface heat flux and temperature after reaching steady state. Details of the experiments setup and conduct could be found elsewhere, El-Genk and Bostanci (2003); Parker and El-Genk (2005); Ali and El-Genk (2010).

\subsection{Objectives}

This paper extends the recent numerical analysis of Ali and ElGenk (2012a and 2012b) by investigating the effects of changing the TIM impedance and the local heat flux at the chip's 1 and $4 \mathrm{~mm}^{2}$ central hot spot (CHS) on the performance of the MPC spreaders. The present numerical analysis uses TIM impedance of 0.02 and $0.19^{\circ} \mathrm{C}$ $\mathrm{cm}^{2} / \mathrm{W}$ and varies the ratio of the heat flux at the CHS to that of the chip's surface average outside the hot spot (HFR) from unity (uniform heat dissipation) to 6 . These analysis parameters are for the purpose of quantifying their effects and do not necessarily represent specific actual applications.

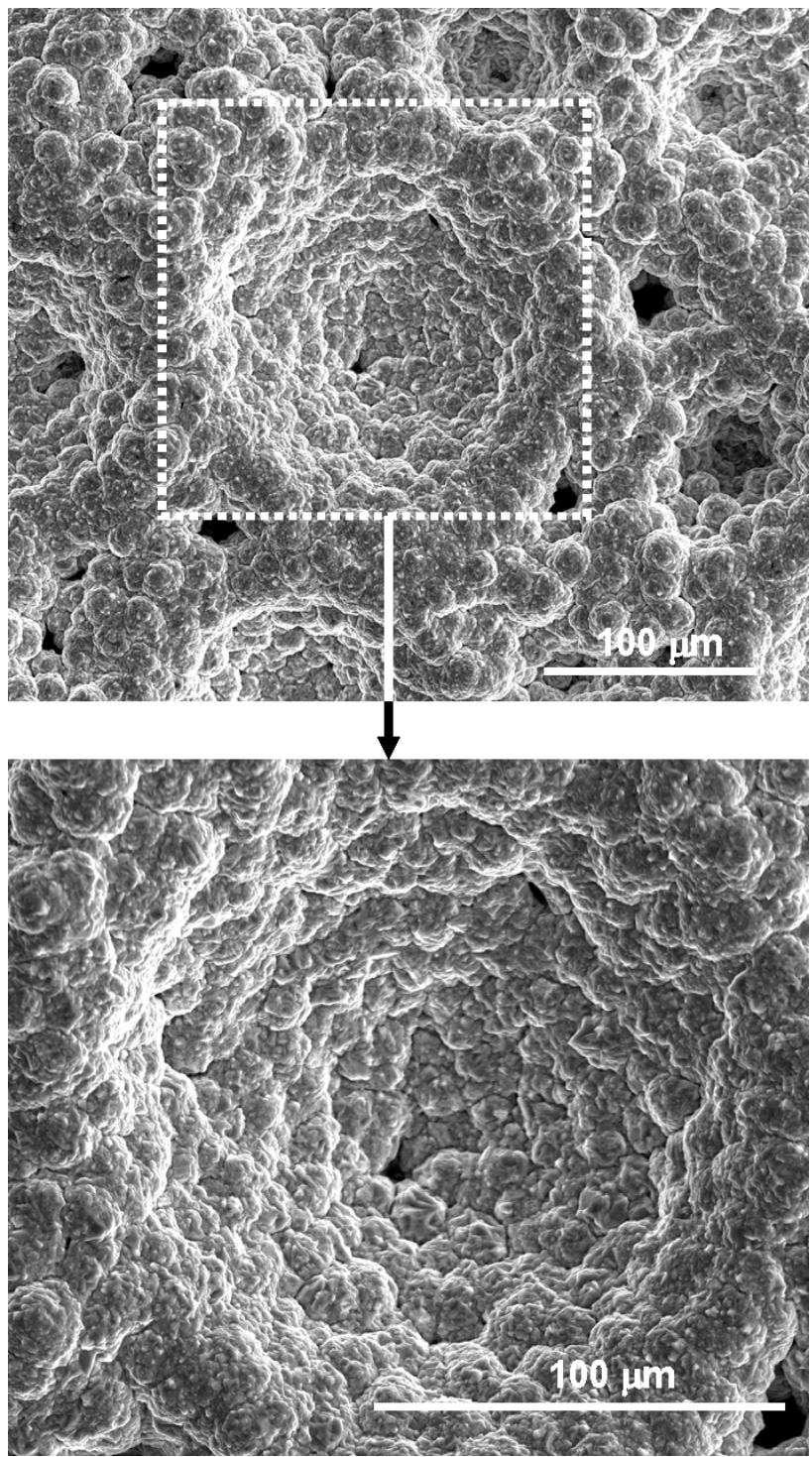

Fig. 1 SEM Images of the $80-\mu \mathrm{m}$ thick MPC Surface.
In the present numerical analysis, the calculated results include: (a) the total thermal power dissipated by the underlying chip and removed by the MPC spreaders; (b) the footprint area and the total thermal resistance of the spreaders; (c) the spatial temperature distributions at the chip and the spreaders' surfaces, and (d) the individual thermal resistances for heat spreading by the $\mathrm{Cu}$ substrates, heat conduction in the MPC surface layer saturated with dielectric liquid, and saturation nucleate boiling on the MPC surface of the spreaders. The results are also compared to those calculated for plane $\mathrm{Cu}$ spreaders of the same thicknesses as the $\mathrm{Cu}$ substrates of the MPC spreaders. The next section presents and discusses the experimental saturation pool boiling curves obtained by the authors for PF-5060 dielectric liquid on the $80-\mu \mathrm{m}$ thick MPC and on plane $\mathrm{Cu}$ surfaces of the same footprint dimensions $(10 \times 10 \mathrm{~mm})$ at $0.085 \mathrm{MPa}$.
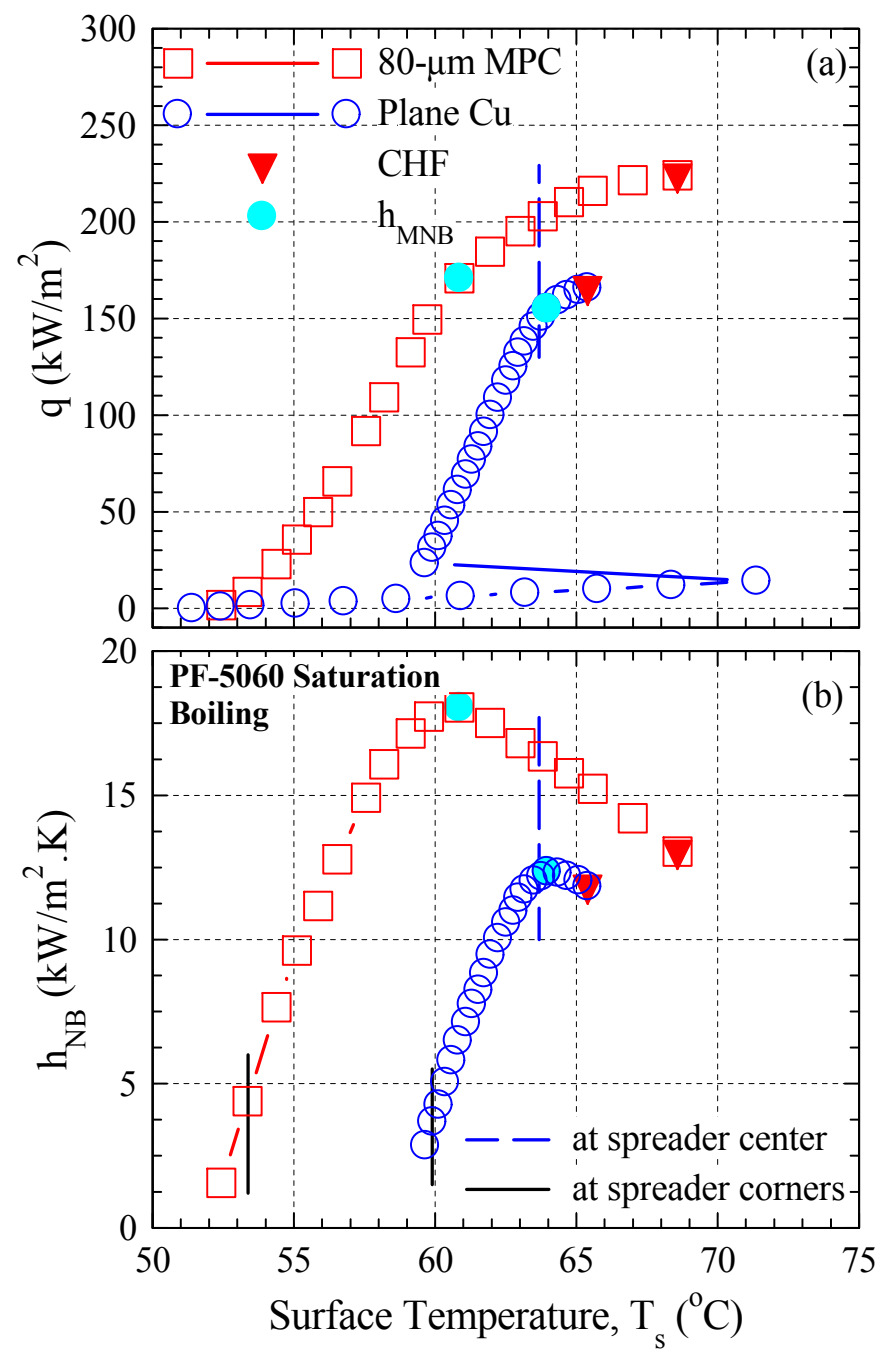

Fig. 2 Saturation pool boiling and $\mathrm{h}_{\mathrm{NB}}$ curves for PF-5060 dielectric liquid at $0.085 \mathrm{MPa}$ on an $80-\mu \mathrm{m}$ thick $\mathrm{MPC}$ and plane $\mathrm{Cu}$ surfaces, El-Genk and Ali (2010).

\section{NUCLEATE POOL BOILING CURVES}

The experimentally obtained saturation boiling curves of PF-5060 dielectric liquid on the $80-\mu \mathrm{m}$ thick MPC and plane $\mathrm{Cu}$ surfaces are compared in Fig. 2a. The MPC surface is deposited on a $10 \times 10 \mathrm{~mm}$ and $1.6 \mathrm{~mm}$-thick $\mathrm{Cu}$ substrate and plane $\mathrm{Cu}$ surface of the same footprint dimensions is prepared with 1500 emery paper. The pool boiling experiments with PF-5060 dielectric liquid are performed in our laboratory at the University of New Mexico in Albuquerque, New Mexico, where the local elevation is $\sim 1700 \mathrm{~m}$ (ambient pressure $~$ 
$0.085 \mathrm{MPa})$. At this elevation, the saturation temperature of PF-5060 liquid $\left(51.4^{\circ} \mathrm{C}\right)$ is lower than at sea level or $0.1 \mathrm{MPa}\left(54^{\circ} \mathrm{C}\right), 3 \mathrm{M}(2012)$. The experimental boiling curves in Fig. $2 \mathrm{a}$ are used to determine those of the nucleate boiling heat transfer coefficient, $\mathrm{h}_{\mathrm{NB}}$ (Fig. $2 \mathrm{~b}$ ).

The filled triangle symbols in Figs. $2 \mathrm{a}$ and $2 \mathrm{~b}$ indicate the Critical Heat Flux (CHF) and the filled circle symbols indicate the maximum nucleate boiling heat transfer coefficient, $\mathrm{h}_{\mathrm{MNB}}$. $\mathrm{CHF}$, caused by the departure from nucleate boiling, is typically associated with a large surge in surface temperature and the transition to film boiling. Thus, $\mathrm{CHF}$ is an operation limit to avoid in practical and industrial applications in which the maximum design heat flux is typically kept at $50-90 \%$ of CHF.

The values of $h_{N B}$ in Fig. $2 b$ increase with increased input power in the experiments due to the increase in the density of the active sites for bubbles nucleation on the MPC and plane $\mathrm{Cu}$ surfaces. At $\mathrm{h}_{\mathrm{MNB}}$, near the end of the fully developed nucleate boiling regime (Fig. 2a), all potential sites for bubbles nucleation become active, with little bubbles coalescence at or near the surface. Thus, $\mathrm{h}_{\mathrm{MNB}}$ is much higher than that at $\mathrm{CHF}$ and the corresponding surface temperature is much lower (Figs. $2 b$ ). Beyond $h_{M N B}$, increasing input power promotes lateral coalescence of growing and rising bubbles at and near the heated surface. The added thermal resistance increases the surface temperature and decreases the value of $h_{\mathrm{NB}}$, until reaching CHF (Fig. 2b).

The saturation boiling experimental curves in Figs. $2 \mathrm{a}$ and $2 \mathrm{~b}$ demonstrate the enhancement in nucleate boiling of PF-5060 dielectric liquid on the $80-\mu \mathrm{m}$ thick MPC surface (Fig. 1), compared to that on plane $\mathrm{Cu}$. The values of $\mathrm{h}_{\mathrm{MNB}}$ and $\mathrm{CHF}$ on the MPC surface (Fig. 1) are 18.1 and $224.1 \mathrm{~kW} / \mathrm{m}^{2}$ and occur at surface temperatures of $60.86^{\circ} \mathrm{C}$ and $68.6^{\circ} \mathrm{C}$ (Fig. 2a). On plane $\mathrm{Cu}$, however, the values of $\mathrm{h}_{\mathrm{MNB}}$ and $\mathrm{CHF}$ are 12.36 and $165.83 \mathrm{~kW} / \mathrm{m}^{2}$ and the corresponding surface temperatures are $64^{\circ} \mathrm{C}$ and $65.4^{\circ} \mathrm{C}$. Fig. 2a also shows a $20^{\circ} \mathrm{C}$ excursion in surface temperature prior to the incipience of nucleate boiling on plane $\mathrm{Cu}$. By contrast, the excursion in surface temperature on the MPC is nil. At CHF, $\mathrm{h}_{\mathrm{NB}}$ for saturation boiling of PF-5060 liquid on the 80$\mu \mathrm{m}$ thick MPC surface is $\sim 13 \mathrm{~kW} / \mathrm{m}^{2} \mathrm{~K} ; \sim 72 \%$ of $\mathrm{h}_{\mathrm{MNB}}\left(18.1 \mathrm{~kW} / \mathrm{m}^{2} \mathrm{~K}\right)$ and occurs at a $7.74^{\circ} \mathrm{C}$ higher surface temperature than at $\mathrm{h}_{\mathrm{MNB}}(\sim 68.6$ ${ }^{\circ} \mathrm{C}$ ). The MPC surface temperature at $\mathrm{h}_{\mathrm{MNB}}$ is $60.86^{\circ} \mathrm{C}$ (Fig. $2 \mathrm{~b}$ ). For immersion nucleate boiling cooling applications, it is desirable to operate at or near $h_{M N B}$. On the left side of the $h_{N B}$ curves (Fig. 2b), the lower surface temperatures help decreasing the junctions' temperature of the underlying chip.

The saturation nucleate boiling heat coefficient curves for PF-5060 liquid in Fig. $2 \mathrm{~b}$ are used in the present numerical thermal analyses of the MPC and the plane $\mathrm{Cu}$ spreaders for cooling a $10 \times 10 \mathrm{~mm}$ chip with 1 and $4 \mathrm{~mm}^{2}$ CHS (Fig. 3). The MPC spreaders comprise a 1.6, 2.4 or 3.2-mm thick $\mathrm{Cu}$ substrate and an $80-\mu \mathrm{m}$-thick MPC surface (Fig. 3) and the plane $\mathrm{Cu}$ spreaders have the same thicknesses as the $\mathrm{Cu}$ substrates of the MPC spreaders. The next section describes the problem statement and the boundary conditions used in the performed 3-D numerical thermal analyses of these spreaders.

Table 1. THERMFLOW ${ }^{\mathrm{TM}} \mathrm{T} 558$ phase-change, $25.4 \mu \mathrm{m}$ thick polymer foils TIM, Thermflow (2012).

\begin{tabular}{|c|c|c|}
\hline $\begin{array}{c}\text { Thermal impedance } \\
\text { @ } 70^{\circ} \mathrm{C}\left({ }^{\circ} \mathrm{C}-\mathrm{cm}^{2} / \mathrm{W}\right)\end{array}$ & $\begin{array}{c}\text { Applied pressure } \\
(\mathrm{kPa})\end{array}$ & $\begin{array}{c}\text { Melting point } \\
\left({ }^{\circ} \mathrm{C}\right)\end{array}$ \\
\hline 0.190 & 69 & 45 \\
0.020 & 172 & \\
0.013 & 345 & \\
\hline
\end{tabular}

\section{PROBLEM STATEMENT AND CONDITIONS}

The MPC spreader is $t_{\mathrm{sp}}$ thick (Fig. 3a) and the $10 \mathrm{x} 10 \mathrm{~mm}$ chip centered below the spreader, $\mathrm{L}_{\mathrm{sp}} \times \mathrm{L}_{\mathrm{sp}}$ (Fig. 3b), has either a 1 or $4 \mathrm{~mm}^{2}$ square CHS. Saturation nucleation boiling of PF-5060 dielectric liquid cools the MPC surface of the spreader. The $\mathrm{Cu}$ substrate, $t_{\mathrm{cu}}$, is either1.6, 2.4 or $3.2 \mathrm{~mm}$-thick and that of the MPC surface layer, $t_{\mathrm{MPC}}$, is $80 \mu \mathrm{m}$ thick. The effective thickness and the thermal impedance of the TIM between the $\mathrm{Cu}$ substrate and underlying chip, $\mathrm{TI}_{\mathrm{TIM}}$, depend on the applied pressure (Table 1).

The THERMFLOW ${ }^{\mathrm{TM}}$ T558 TIM used in the numerical analysis is a phase-change, electrically nonconductive, and thermally enhanced polymer for high power chips and electronic packaging applications, Thermflow (2012). This solid material at room temperature becomes soft at high temperatures $\left(>45^{\circ} \mathrm{C}\right)$, and conforms to the matting surfaces of the interface with a light clamping pressure. The impedance of TIM is $0.19^{\circ} \mathrm{C}-\mathrm{cm}^{2} / \mathrm{W}$ at a clamping pressure of $69 \mathrm{kPa}$ and $70^{\circ} \mathrm{C}$ and $0.02^{\circ} \mathrm{C}-\mathrm{cm}^{2} / \mathrm{W}$ at a $172 \mathrm{kPa}$ clamping pressure, Thermflow (2012). For a conservative consideration, the base-case numerical analyses of the MPC and plane $\mathrm{Cu}$ spreaders use TIM impedance of $0.19^{\circ} \mathrm{C}-\mathrm{cm}^{2} / \mathrm{W}$. The effect of decreasing this impedance to $0.02^{\circ} \mathrm{C}-\mathrm{cm}^{2} / \mathrm{W}$ on the spreaders' performance is also investigated.

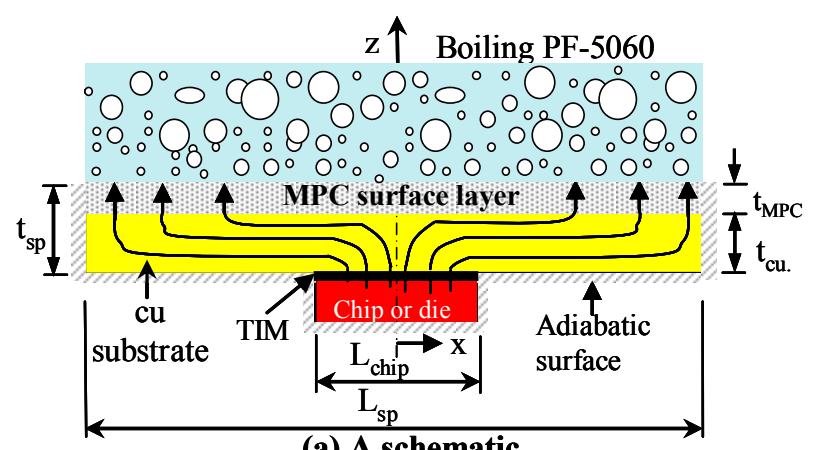

(a) A schematic

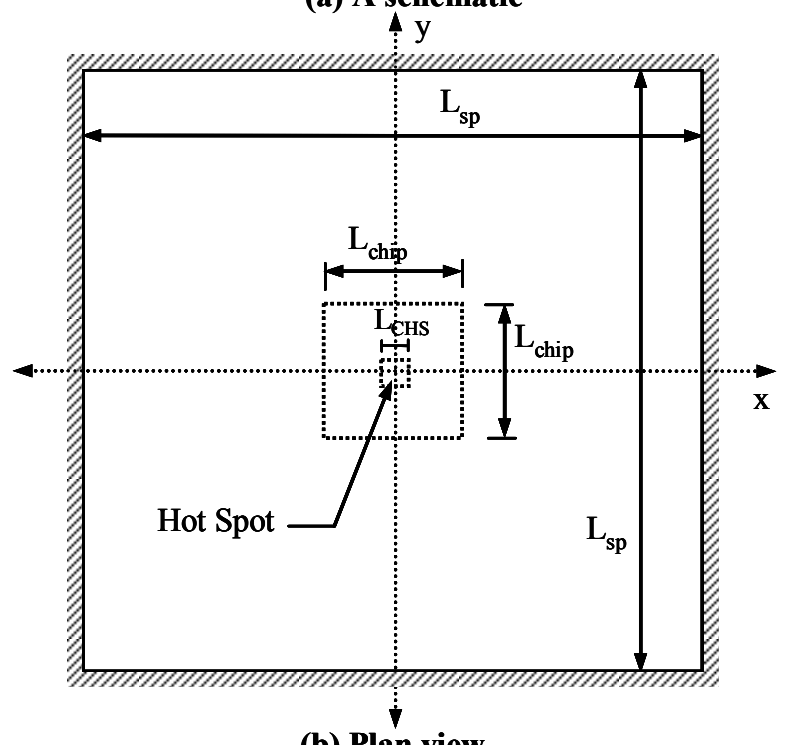

(b) Plan view

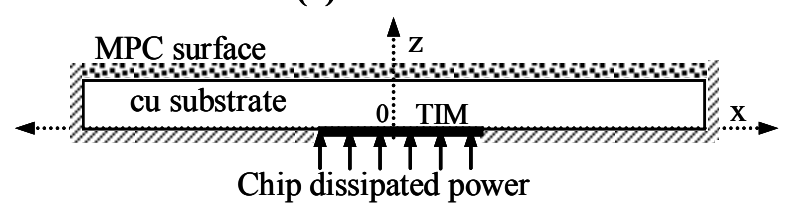

(c) Elevation plan

Fig. 3 A Schematic and a cross-sectional view of the MPC spreader.

In addition to the dimensions of the spreaders' footprints, the numerical analyses calculate the thermal powers removed by the spreaders and the spatial temperature distributions at their surfaces and the surface of the underlying chip. The calculated results also include the individual thermal resistances for the heat spreading in the $\mathrm{Cu}$ substrate, heat conduction in the MPC layer, and saturation boiling of the PF-5060 dielectric liquid. The total thermal resistances of the MPC 
spreaders, $\mathrm{R}_{\text {TOT }}$, are the sum of these three thermal resistances plus that of the TIM, $\mathrm{R}_{\mathrm{TIM}}$. For the plane $\mathrm{Cu}$ spreaders, the total thermal resistances are the sum of those of the TIM, heat spreading, and saturation boiling.

Although the heat removed from the sides and bottom of the spreaders could partially contribute to cooling the underling chip, conservatively the present numerical analyses assume these surfaces adiabatic (Figs. 3a-3c). In practical applications, the heat transfer coefficients at these surfaces, likely by forced convection of air, are not well characterized. Thus, the calculated values of the removed thermal powers by the MPC and plane $\mathrm{Cu}$ spreaders in the present analyses would be lower and the corresponding chip maximum surface temperatures would be higher than in actual applications.

The thermal conductivity of $\mathrm{Cu}(400 \mathrm{~W} / \mathrm{m} \mathrm{K})$, the effective thermal conductivity of the $80-\mu \mathrm{m}$ thick MPC surface layer saturated with PF-5060 liquid ( $191.63 \mathrm{~W} / \mathrm{m} \mathrm{K})$ and the thermal conductance of TIM, Thermflow (2012), are specified in the input to the numerical thermal analyses of the MPC spreaders. The effective thermal conductivity of the $80-\mu \mathrm{m}$ thick MPC surface layer is calculated in terms of its effective volume porosity $(0.521)$ and the thermal conductivities of $\mathrm{Cu}$ and the PF-5060 dielectric liquid, El-Genk and Ali (2010); 3M (2012).

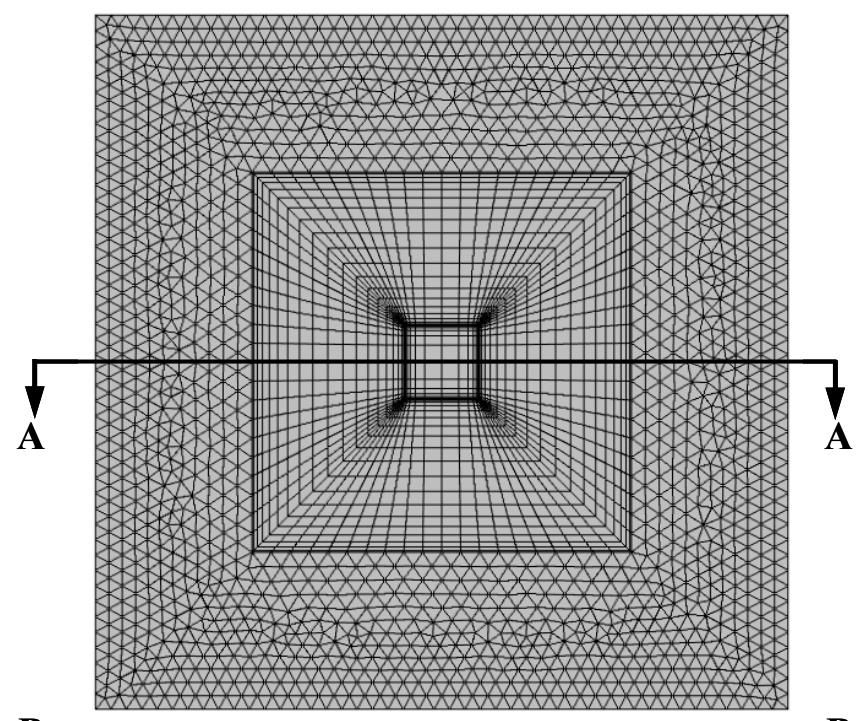

$\stackrel{\text { B }}{4}$

(a) Plan view, B-B

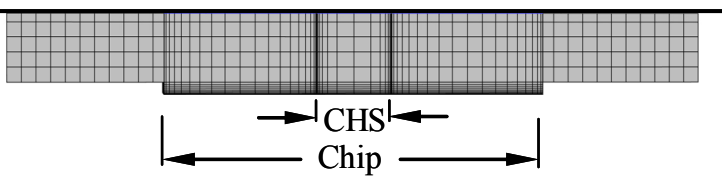

(b) Cross-sectional view, A-A

Fig. 4 Numerical mesh grid used in the present numerical thermal analyses of the Spreaders.

The thermal powers removed from the spreaders' surfaces by saturation boiling of PF-5060 and the spreaders' footprint areas are calculated, subject to the following limits: (a) $h_{\mathrm{NB}}$ at the center of the spreader surface is that determined in the pool boiling experiments of El-Genk and Ali (2010) at $90 \%$ of CHF (Fig. 2b) and (b) $h_{N B}$ at the corners of the spreader top surface is that measured in the pool boiling experiments at a $1{ }^{\circ} \mathrm{C}$ higher surface temperature than that at incipient boiling (Fig. 2b). The local heat flux at the CHS of the underlying chip is assumed uniform, but varied from 2 - 6 times the average surface heat flux of the chip outside the hot spot. For comparison, numerical thermal analyses are also performed for an underling chip without a CHS (uniform heat dissipation or HFR $=1$ ). The steady-state numerical thermal analyses of the MPC spreaders (Fig. 3) involve 3-D conduction $(\mathrm{x}, \mathrm{y}, \mathrm{z})$ in the $\mathrm{Cu}$ substrate and in the $80-\mu \mathrm{m}$ MPC surface layer. However, the results showed that heat conduction in the MPC surface layer is effectively one-dimensional (Fig. 3a). This is because the effective thermal conductance of this thin layer, saturated with PF-5060 liquid $\left(2.39 \times 10^{6} \mathrm{~W} / \mathrm{m}^{2} \mathrm{~K}\right)$, is higher than that of the $1.6-3.2 \mathrm{~mm}$ thick $\mathrm{Cu}$ substrate $\left(1.25 \times 10^{5}-2.5 \times 10^{5} \mathrm{~W} / \mathrm{m}^{2} \mathrm{~K}\right)$.

The 3-D numerical analyses of the MPC and plane $\mathrm{Cu}$ spreaders (Fig. 3) are performed using the commercial software, COMSOL multiphysics version 4.0a, COMSOL MULTIPHYSICS (2010). This finite elements software solves the steady-state heat conduction in the $\mathrm{Cu}$ substrate and the MPC surface layer using a stationary iterative solver with a generalized minimum residual algorithm (GMRES). With an implemented tolerance of $1.0 \times 10^{-4}$, the fine numerical mesh grid ensures the solution convergence and the accuracy of the results.

The implemented numerical meshing in thermal analyses of the MPC and plan $\mathrm{Cu}$ spreaders is shown in Fig. 4. The implemented numerical grid comprises quadrilateral mesh elements in the $10 \times 10$ $\mathrm{mm}$ central section of the spreader, directly above the underlying chip, and hexahedral elements in the rest of the spreader. Figure 4 a shows the applied numerical mesh grid elements at the surface of the spreader. The cross-sectional view in Fig. $4 \mathrm{~b}$ shows the numerical grid used in the $\mathrm{Cu}$ substrate and the MPC surface layer. The total number of mesh grid elements used in the thermal analyses of the MPC spreader increases as the thickness of the $\mathrm{Cu}$ substrate increases. A total of 45,000 elements are used in the numerical thermal analysis of the MPC spreader with a $1.6-\mathrm{mm}$ thick $\mathrm{Cu}$ substrate and as much as 350,000 elements for the MPC spreader with a 3.2-mm thick $\mathrm{Cu}$ substrate.

The thermal analyses of the MPC and the plane $\mathrm{Cu}$ spreaders are carried out using iterative procedures. First, initial values of the spreader's footprint dimensions and the dissipated thermal power by the underlying chip are assumed. These values changed incrementally until the values of the $\mathrm{h}_{\mathrm{NB}}$ at the center of the spreader surface equals that corresponding to $90 \%$ of CHF (Fig. $2 \mathrm{~b}$ ). Then, the numerical thermal analyses continue to incrementally increase the values of both the dissipated power by the underlying chip and the footprint dimensions of the spreader until also $h_{\mathrm{NB}}$ at the corners of the spreader surface equals that corresponding to a $1^{\circ} \mathrm{C}$ higher surface temperature than measured in the boiling experiments at incipient boiling (Fig. 2b). When both desired values of $h_{\mathrm{NB}}$ at the center and the corners of the spreader are reached and a convergence of the numerical solution is achieved, the calculations are terminated. Calculations are also performed using only a quarter of the spreader with symmetry boundary conditions without a change in the numerical results. A typical case took $\sim 10$ minutes on a recent personal computer to complete.

The accuracy of numerical calculations is verified by examining the error in the overall energy balance calculations. With a solver tolerance of $1.0 \times 10^{-4}$, the error in the overall energy balance is $\sim 0.1 \%$. To examine the sensitivity of the numerical solution convergence and the accuracy of the results to the number of numerical mesh elements used in the numerical analysis, calculations are repeated using a finer numerical grid of 600,000 elements. There were insignificant changes in the solution convergence and the calculated results.

\section{RESULTS AND DISCUSSION}

The performed thermal analyses of the MPC and plane $\mathrm{Cu}$ spreaders are for steady-state condition. They calculate the spreaders' footprint areas and thermal powers removed; the temperature distributions at the surface of the spreaders and that of the underlying chip; the chip maximum temperature at CHS and the individual thermal resistances for heat spreading in $\mathrm{Cu}$ substrates, heat conduction in TIM and the MPC surface layer, and saturation nucleate boiling at the top surface of the spreaders. The analyses varied the values of: (a) the CHS area $\left(1\right.$ and $\left.4 \mathrm{~mm}^{2}\right)$ and local heat flux ratio, HFR, from $1-6$ and (b) the thickness of the $\mathrm{Cu}$ substrate $(1.6,2.4$ and $3.2 \mathrm{~mm})$, and the thermal impedance of TIM.. The performance results of the spreaders with a 
$\mathrm{TI}_{\mathrm{TIM}}=0.19^{\circ} \mathrm{C}-\mathrm{cm}^{2} / \mathrm{W}$ are presented in Figs. $5-12$ and those in Figs $13-17$ show the effect of using smaller TIM impedance of $0.02{ }^{\circ} \mathrm{C}$ $\mathrm{cm}^{2} / \mathrm{W}$.

\subsection{Thermal Power Removed}

The results for HFR $=2$ and 6 , CHS areas of 1 and $4 \mathrm{~mm}^{2}$ and $\mathrm{Cu}$ substrate thicknesses of 1.6 and $3.2 \mathrm{~mm}$ are compared in Figs. $5 \mathrm{a}-5 \mathrm{~d}$. Increasing the thickness of the $\mathrm{Cu}$ substrate increases the removed thermal power by and the footprint area of the MPC spreaders. Conversely, increasing HFR at CHSs slightly decreases the thermal powers removed from the spreaders' surfaces and their footprint areas. These effects are more pronounced for the underlying chip with 4.0 $\mathrm{mm}^{2} \mathrm{CHS}$ and HFR $=6$ (Figs. $5 \mathrm{~b}$ and $5 \mathrm{~d}$ ). The total thermal powers removed and the footprint areas of the plane $\mathrm{Cu}$ spreaders are significantly smaller than those of the MPC spreaders (Figs. 5a-5d).
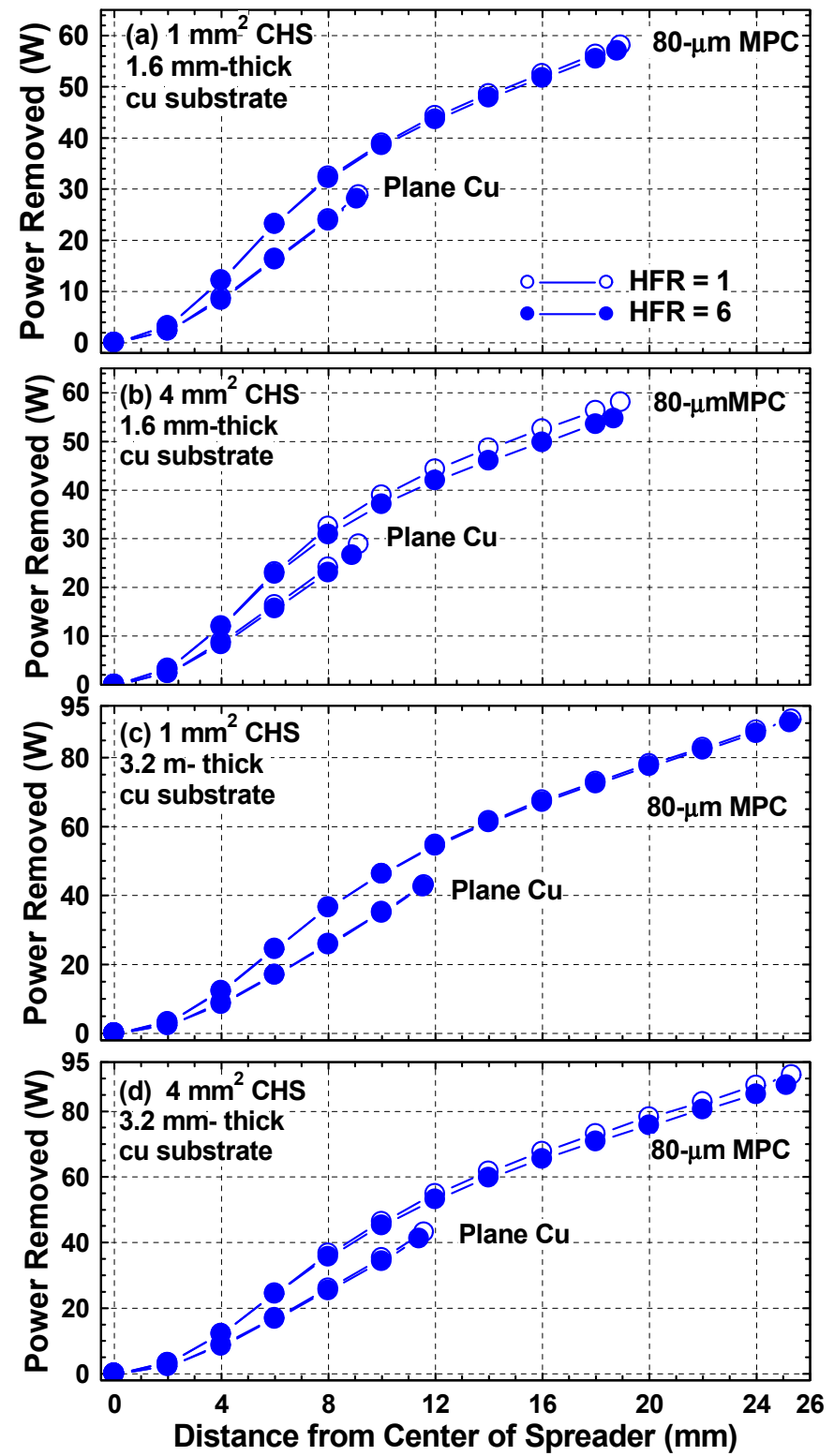

Fig. 5 Comparisons of the thermal powers removed using MPC and plane $\mathrm{Cu}$ spreaders.

A measure of spreader performance is the ratio of its thickness to width, $t_{s p} / L_{s p}$; the smaller the ratio the higher the spreader performance. The ratios of 0.0444 (Fig. 5a) and 0.0653 (Fig. 5d) for MPC (or composite) spreaders with 1.6 and $3.2 \mathrm{~mm}$ thick $\mathrm{Cu}$ substrates, respectively, are less than half those for plane $\mathrm{Cu}$ spreaders of the same thicknesses as the $\mathrm{Cu}$ substrates of MPC spreaders; 0.098 and 0.1474, respectively.

The MPC spreader with a $1.6 \mathrm{~mm}$ thick $\mathrm{Cu}$ substrate has a footprint area of $14.14 \mathrm{~cm}^{2}$ and removes $56.95 \mathrm{~W}$ for the underlying chip with a $1 \mathrm{~mm}^{2}$ CHS when HFR $=6$ (Fig. 5a). With no CHS (or uniform heat dissipation by the underlying chip $(\mathrm{HFR}=1)$ these values are $14.33 \mathrm{~cm}^{2}$ and $58.05 \mathrm{~W}$, respectively. The values for the plane $\mathrm{Cu}$ spreader that is $1.6 \mathrm{~mm}$ thick are only $3.29 \mathrm{~cm}^{2}$ and $28.1 \mathrm{~W}$ for the chip with $1 \mathrm{~mm}^{2}$ CHS when HFR $=6$ and $3.35 \mathrm{~cm}^{2}$ and $28.78 \mathrm{~W}$ when there is no CHS (HFR = 1) (Fig. 5a).

For the MPC spreader with a $1.6 \mathrm{~mm}$ thick $\mathrm{Cu}$ substrate, increasing the CHS area from 1 to $4 \mathrm{~mm}^{2}$, while keeping $\mathrm{HFR}=6$, slightly decreases the thermal power removed to $54.7 \mathrm{~W}$ and the spreader's footprint area to $13.95 \mathrm{~cm}^{2}$ (Fig. 5b). When HFR $=6$ and the CHS area is 1 and $4 \mathrm{~mm}^{2}$, the MPC spreaders with $3.2-\mathrm{mm}$ thick $\mathrm{Cu}$ substrate have larger footprint areas of 25.5 and $25.25 \mathrm{~cm}^{2}$ and remove as much as $90.1 \mathrm{~W}$ and $87.85 \mathrm{~W}$, respectively (Figs. 5c and 5d).
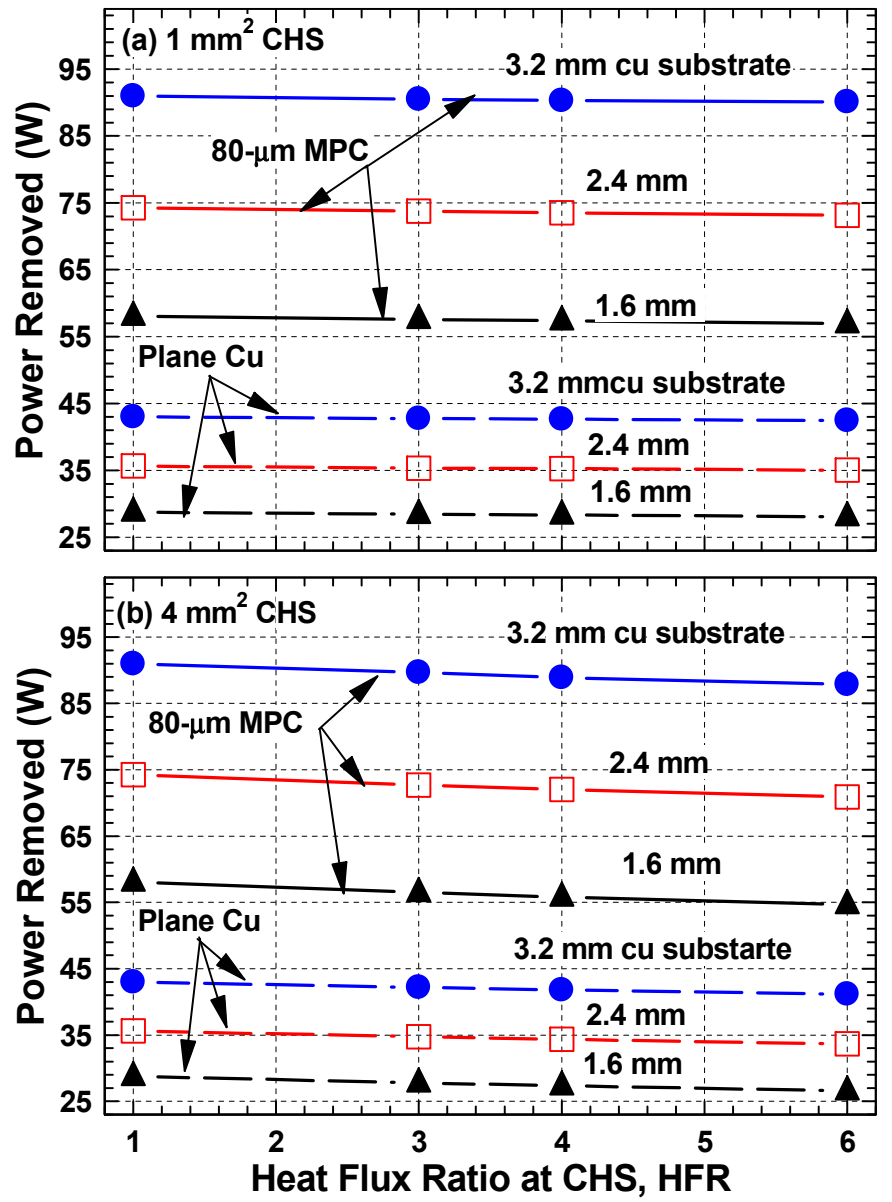

Fig. 6 Effects of CHS area and HFR and $\mathrm{Cu}$ substrate thickness on the thermal powers removed by MPC and plane $\mathrm{Cu}$ spreaders.

\subsection{Effect of HFR at CHS on Spreaders' Performance}

The thermal powers removed by the MPC spreaders with different $\mathrm{Cu}$ substrate thicknesses are plotted in Figs. $6 \mathrm{a}$ and $6 \mathrm{~b}$ versus the HFR at the CHS in the underlying chip. Results for the plane $\mathrm{Cu}$ spreaders are also shown in these figures for comparison. With a $1 \mathrm{~mm}^{2} \mathrm{CHS}$, increasing HFR from 1 (uniform heat dissipation) to 6 decreases slightly the thermal power removed by the MPC spreader with a 3.2$\mathrm{mm}$ thick $\mathrm{Cu}$ substrate from $91.0 \mathrm{~W}$ to $90.1 \mathrm{~W}$, compared to 58.05 and $56.95 \mathrm{~W}$ for the MPC spreader with a thinner substrate of $1.6 \mathrm{~mm}$. For the same CHS area of $1 \mathrm{~mm}^{2}$, the $3.2 \mathrm{~mm}$ and $1.6 \mathrm{~mm}$ thick plane $\mathrm{Cu}$ spreaders have smaller footprint areas and remove much less thermal 
powers than the MPC spreaders: $43 \mathrm{~W}$ and $28.78 \mathrm{~W}$ when $\mathrm{HFR}=1$ and $42.47 \mathrm{~W}$ and $28.1 \mathrm{~W}$ when HFR $=6$ (Fig. 6a). The results for the underlying chip with $4 \mathrm{~mm}^{2}$ CHS are similar, except that the removed thermal powers by the MPC and plane $\mathrm{Cu}$ spreaders and their footprint areas are slightly smaller (Fig. 6b). With a $4 \mathrm{~mm}^{2}$ CHS area, the MPC spreader with a $3.2 \mathrm{~mm}$ thick $\mathrm{Cu}$ substrate removes $87.85 \mathrm{~W}$ when HFR $=6$. This power is significantly higher than the $41.16 \mathrm{~W}$ removed by the plane $\mathrm{Cu}$ spreader of almost the same thickness (Fig. 6b). In addition to the total thermal power removed and the spreader' footprint area, the HFR at CHS affects the maximum and the spatial distribution of the chip surface temperature.

\subsection{Chip Surface Temperature Distribution}

The plane $\mathrm{Cu}$ and MPC spreaders effectively decrease the chip surface temperature and mitigate the effect of the CHS areas on the local maximum temperature of the chip at CHS (Figs. 7a and 7b). The MPC (or composite) spreaders remove much more thermal powers and have larger footprint areas than the plane $\mathrm{Cu}$ spreaders, but increase the maximum surface temperature of the underlying chip at CHS. However, the ratio of the chip maximum to the average surface temperature is only a fraction of the HFR at the CHS (Fig. 7). Increasing the Chip's CHS area and the thickness of the $\mathrm{Cu}$ spreaders, or the $\mathrm{Cu}$ substrates of the MPC spreaders, increase the chip maximum temperature at CHS.
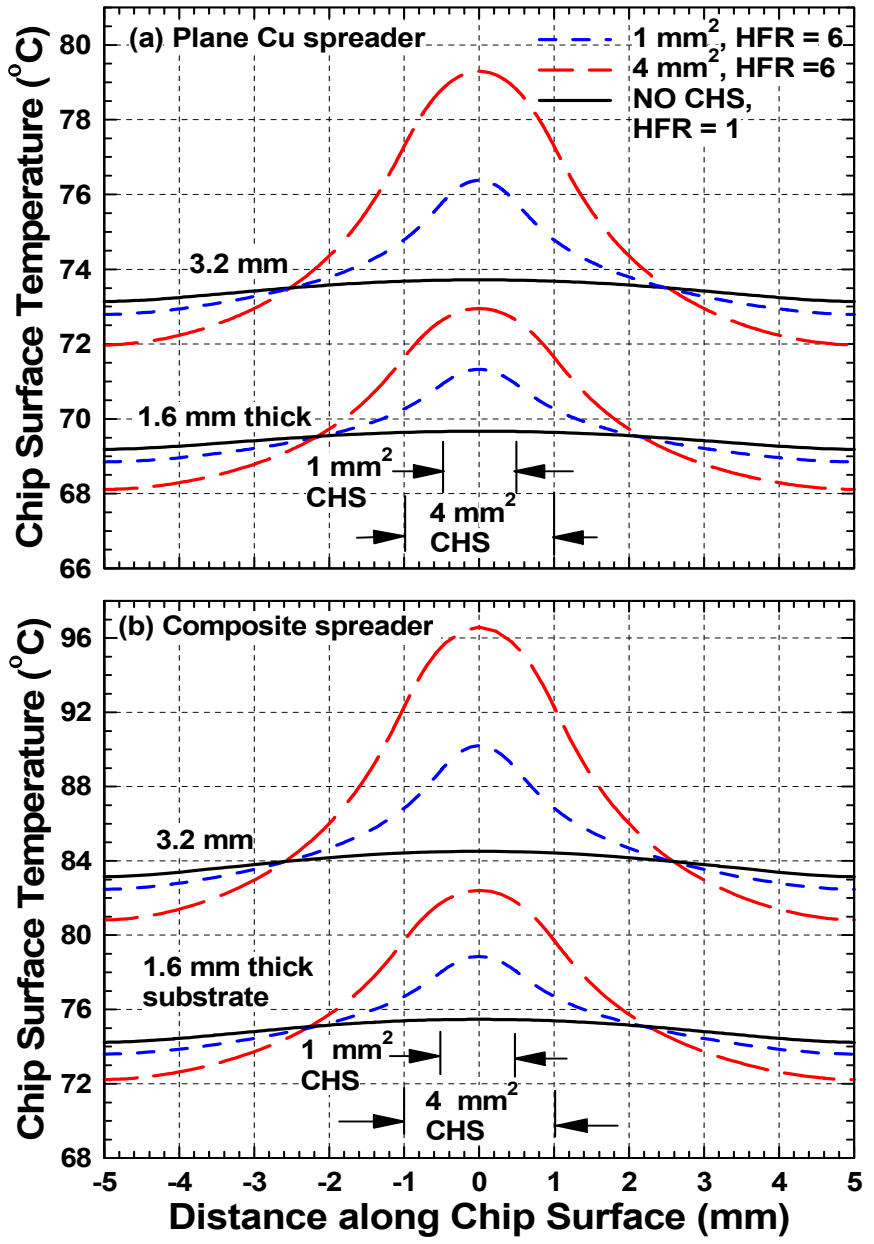

Fig. 7 Effects of CHS area and HFR and thickness of $\mathrm{Cu}$ substrate on the chip's surface and maximum temperatures.

With a $3.2 \mathrm{~mm}$ thick plane $\mathrm{Cu}$ spreader, when $\mathrm{HFR}=6$ the calculated maximum surface temperatures of the chip at the 1 and 4 $\mathrm{mm}^{2} \mathrm{CHSs}$ are $76.37^{\circ} \mathrm{C}$ and $79.29^{\circ} \mathrm{C}$. These temperatures are only 2.65 and $5.57^{\circ} \mathrm{C}$ higher, respectively, than that with a uniform heat dissipation, $73.72^{\circ} \mathrm{C}(\mathrm{HFR}=1)$. For the MPC spreader with a $3.2 \mathrm{~mm}$ thick $\mathrm{Cu}$ substrate, the chip maximum surface temperature at the 1 and $4 \mathrm{~mm}^{2} \mathrm{CHS}$, when HFR $=6$ (Fig. $7 \mathrm{~b}$ ), are 91.16 and $96.6^{\circ} \mathrm{C}$, respectively, compared to $84.5^{\circ} \mathrm{C}$ for the chip with a uniform heat dissipation (Fig. 7b). Decreasing the thickness of the plane $\mathrm{Cu}$ spreader or the $\mathrm{Cu}$ substrate of MPC spreader from 3.2 to $1.6 \mathrm{~mm}$ markedly decreases the chip's maximum surface temperature and the temperature differential across the chip (Figs. $7 \mathrm{a}$ and $7 \mathrm{~b}$ ). It also decreases the thermal power removed and the spreader's footprint area. The next subsection compares the calculated performance surfaces of the plane $\mathrm{Cu}$ and MPC (or composite) spreaders at the same conditions (Figs. 8).

\subsection{Spreaders' Performance Surfaces}

The performance surfaces for the MPC (or composite) and plane $\mathrm{Cu}$ spreaders are compared in Figs. $8 \mathrm{a}$ and $8 \mathrm{~b}$. These surfaces are grids compromised of equal-thickness lines of the $\mathrm{Cu}$ spreaders or the $\mathrm{Cu}$ substrate of the MPC spreaders (1.6, 2.4 and $3.2 \mathrm{~mm}$ ), and intersecting lines of the HFR at the CHS in the underlying chip $(1-6)$. The performance surfaces in Fig. 8a are for a chip with a $1 \mathrm{~mm}^{2}$ CHS and those in Fig. $8 \mathrm{~b}$ are for a chip with a $4 \mathrm{~mm}^{2}$ CHS. The performance surface for the MPC (or composite) spreaders is much wider than for the plane $\mathrm{Cu}$ spreaders of almost the same thicknesses.

Increasing the CHS area expands the performance surface of the MPC spreaders, but only slightly that of the plane $\mathrm{Cu}$ spreaders (Figs. $8 \mathrm{a}$ and $8 \mathrm{~b}$ ). The thermal powers removed by the MPC spreaders are $\sim 2$ times those removed by the plane $\mathrm{Cu}$ spreaders of almost the same thicknesses, when the CHS area is $1 \mathrm{~mm}^{2}$ (Fig. 8a). However, the corresponding chip maximum surface temperatures are $5.79-13.36^{\circ} \mathrm{C}$ higher than with the plane $\mathrm{Cu}$ spreaders (Figs. 8a and 8b). This is because the thermal powers removed by MPC (or composite) spreaders are higher and the footprint areas are larger than those of the plane $\mathrm{Cu}$ spreaders.
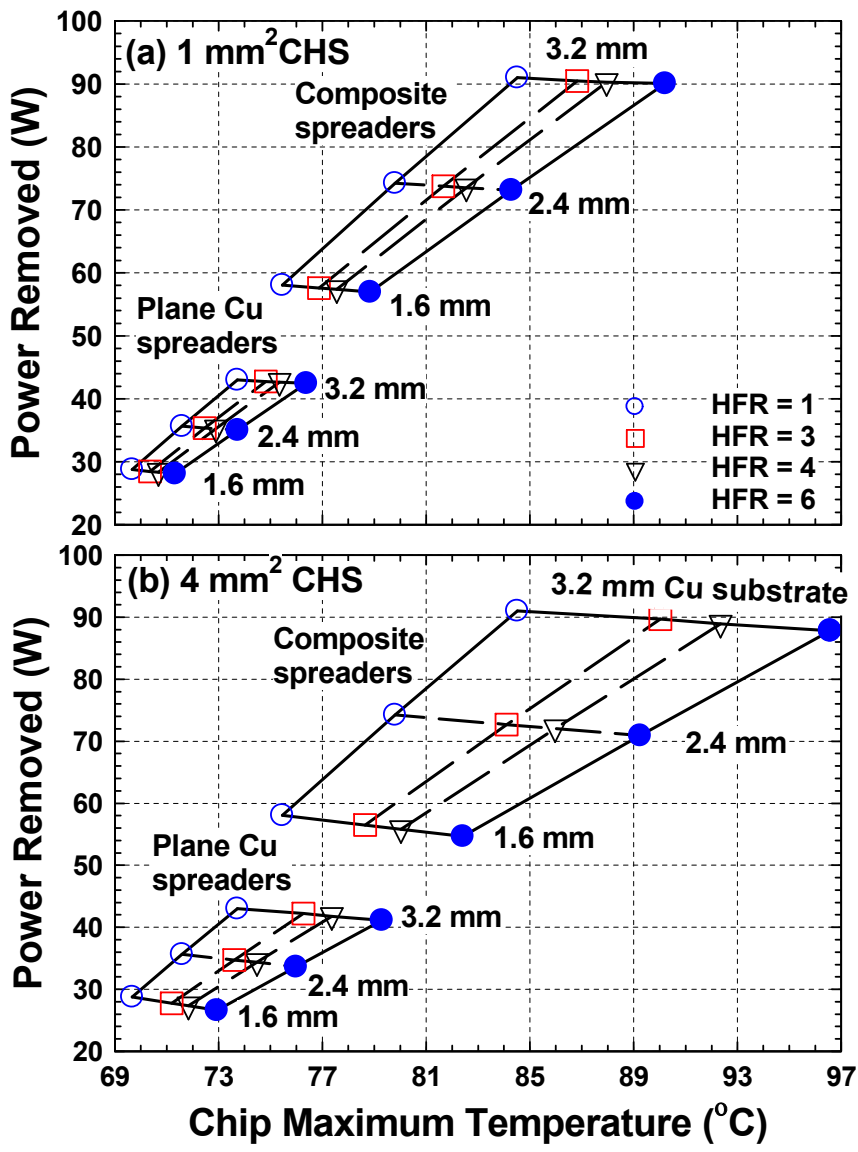

Fig. 8 Performance surfaces for MPC and plane $\mathrm{Cu}$ spreaders. 
For a MPC spreader with a $1.6 \mathrm{~mm}$ thick $\mathrm{Cu}$ substrate, when HFR $=6$ the local heat flux at the $1 \mathrm{~mm}^{2}$ and $4 \mathrm{~mm}^{2}$ CHS of the underlying chip is 325.43 and $273.3 \mathrm{~W} / \mathrm{cm}^{2}$, respectively. For the same HFR, increasing the thickness of the $\mathrm{Cu}$ substrate of the MPC spreader to 3.2 $\mathrm{mm}$ increases the local heat flux at the $1 \mathrm{~mm}^{2}$ and $4 \mathrm{~mm}^{2}$ CHS to 514.85 and $439.25 \mathrm{~W} / \mathrm{cm}^{2}$, respectively (Figs. 8a and $8 \mathrm{~b}$ ). With plane $\mathrm{Cu}$ spreaders, the removed thermal powers and the local heat fluxes at the Chip's CHSs are much lower than with the MPC spreaders. For a $1.6 \mathrm{~mm}$ thick plane $\mathrm{Cu}$ spreader, when $\mathrm{HFR}=6$ the local heat flux at the chip's 1 and $4 \mathrm{~mm}^{2}$ CHSs is $160.6 \mathrm{~W} / \mathrm{cm}^{2}$ and $133 \mathrm{~W} / \mathrm{cm}^{2}$, respectively.

For the same HFR, increasing the thickness of the plane $\mathrm{Cu}$ spreader to $3.2 \mathrm{~mm}$ increases the local heat flux at the 1 and $4 \mathrm{~mm}^{2}$ CHS of the chip to $242.7 \mathrm{~W} / \mathrm{cm}^{2}$ and $205.8 \mathrm{~W} / \mathrm{cm}^{2}$, respectively (Figs. $8 \mathrm{a}$ and $8 \mathrm{~b}$ ). The distinct differences in the performance of the MPC (or composite) and plane $\mathrm{Cu}$ spreaders affect their total thermal resistances and the maximum surface temperatures of the underlying chip. These effects and the values of the individual thermal resistances as well as the total thermal resistances of the plane $\mathrm{Cu}$ and MPC (or composite) spreaders are discussed next.

\subsection{Spreaders' Thermal Resistances}

The total thermal resistance, $R_{T O T}$, of the MPC spreaders is the sum of those for: (a) saturation boiling, $R_{\text {boil }}$, at the spreader surface, (b) heat conduction in the $80-\mu \mathrm{m}$ MPC surface layer saturated with PF-5060 dielectric liquid, $R_{M P C}$, (c) heat conduction in the TIM between the $\mathrm{Cu}$ substrate and the underling chip, $R_{T I M}$, and (d) heat spreading in the $\mathrm{Cu}$ substrate, $R_{s p}$, as:

$$
R_{T O T}=\left(T_{c h i p \text {, } \max }-T_{s a t}\right) / Q=R_{T I M}+R_{s p}+R_{M P C}+R_{\text {boil }} .
$$

The individual thermal resistances in this equation are defined as:

$$
\begin{aligned}
& R_{T I M}=T I_{T I M} / A_{\text {chip }}, \\
& R_{s p}=\left(T_{c h i p \max }-\bar{T}_{c u}\right) / Q-R_{T I M}, \\
& R_{M P C}=\left(\bar{T}_{c u}-\bar{T}_{s, M P C}\right) / Q, \\
& R_{b o i l}=\left(\bar{T}_{s, M P C}-T_{s a t}\right) / Q .
\end{aligned}
$$

The average surface temperatures of the $\mathrm{Cu}$ substrate, $\bar{T}_{C u}$, and the MPC surface layer, $\bar{T}_{s, M P C}$, are expressed, respectively, as:

$$
\begin{aligned}
& \bar{T}_{c u}=\left(\int_{-0.5 L_{s p}}^{+0.5 L_{s p}} \int_{-0.5 L_{s p}}^{+0.5 L_{s p}} T_{c u}(x, y) d x d y\right) / L_{s p}^{2}, \\
& \bar{T}_{s, M P C}=\left(\int_{-0.5 L_{s p}}^{+0.5 L_{s p}+0.5 L_{s p}} \int_{s, M P C} T_{s,}(x, y) d x d y\right) / L_{s p}^{2} .
\end{aligned}
$$

For the plane $\mathrm{Cu}$ spreader, the total resistance is given as:

$$
R_{\text {TOT }}=\left(T_{\text {chip }, \max }-T_{\text {sat }}\right) / Q=R_{T I M}+R_{s p}+R_{\text {boil }} .
$$

While the $R_{T I M}$ is independent of the total thermal power removed by the spreaders, $Q$, (Eq. 2), the values of $R_{b o i l}, R_{M P C}, R s p$, and hence the spreader's total resistance, $R_{T O T}$ depend on the thermal power removed, $Q$, the chip maximum surface temperature at CHS, and the average top surface temperatures of the $\mathrm{Cu}$ substrate and the MPC surface layer. Note that for the same $T I_{T I M}$, increasing the chip's footprint area would decrease the TIM's thermal conduction resistance, $R_{T I M}$. The individual and total thermal resistances for the plane $\mathrm{Cu}$ and MPC (or composite) spreaders are plotted in Figs. 9a and 9b versus the HFR, for the underlying chip with $4 \mathrm{~mm}^{2} \mathrm{CHS}$. The results in these figures are for different thicknesses of the $\mathrm{Cu}$ substrate in the MPC spreaders and of the plane $\mathrm{Cu}$ spreaders $(1.6,2.4$ and $3.2 \mathrm{~mm})$. The heat spreading resistance, $R_{s p}$, is practically independent of the thickness of the plane $\mathrm{Cu}$ spreaders, but increases linearly with increasing the HFR
(Fig. 9a). For the MPC (or composite) spreaders, however, the heat spreading resistance, $R_{s p}$ increases slightly as the thickness of the $\mathrm{Cu}$ substrate increases (Fig. 9b). For both the MPC and plane $\mathrm{Cu}$ spreaders, $R_{s p}$ increases linearly with the HFR.
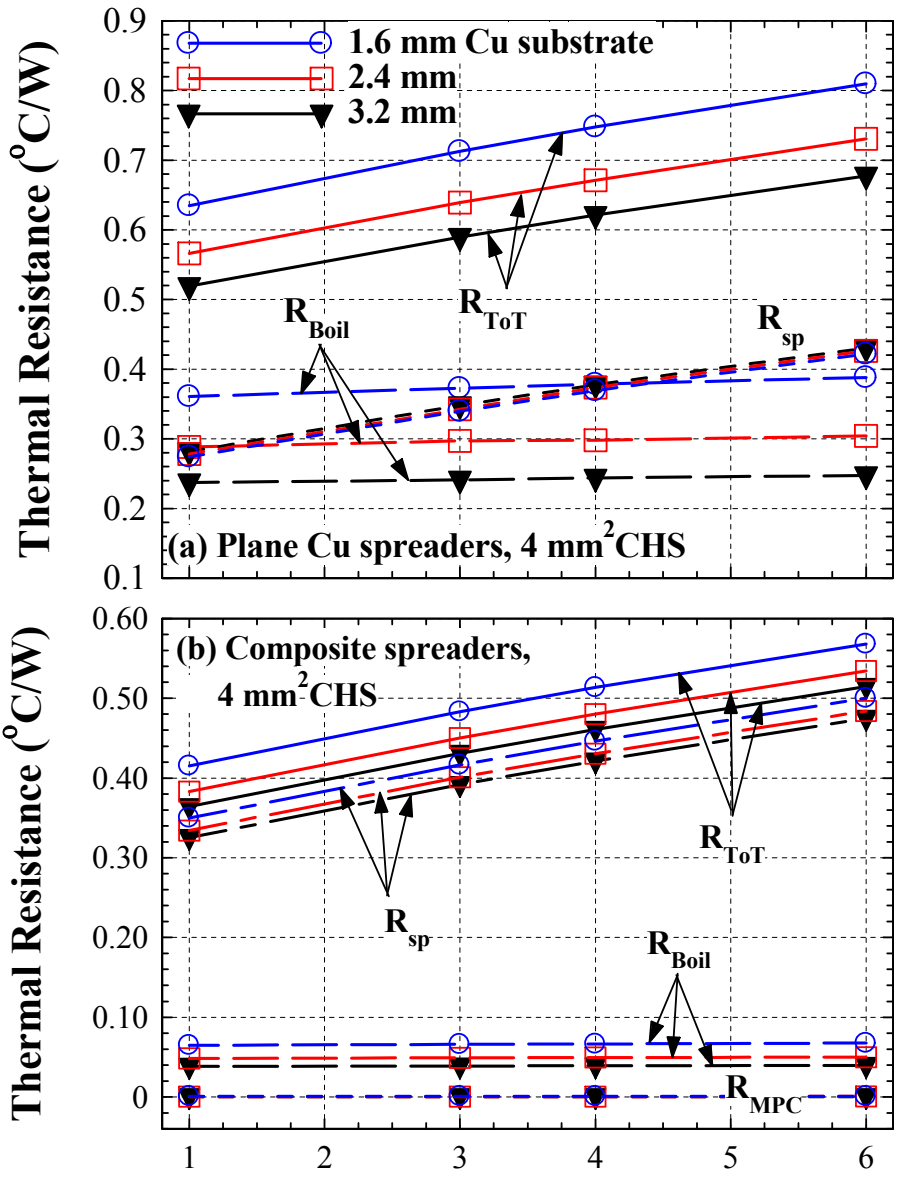

\section{Heat Flux Ratio at CHS, HFR}

Fig. 9 Thermal resistances for MPC and plane $\mathrm{Cu}$ spreaders.

The boiling resistance, $R_{\text {Boil }}$, is almost independent of the HFR for the CHSs of the underlying chip, but that for the MPC surface layer is much lower than that for saturation boiling of PF-5060 dielectric liquid on plane $\mathrm{Cu}$ (Figs. 9a and 9b). This is because the values of nucleate boiling heat transfer coefficients on MPC are much higher than that on plane $\mathrm{Cu}$ (Fig. 2b) and the corresponding surface temperatures are lower (Fig. 2b). On the other hand, the larger footprint areas of MPC (or composite) spreaders increase their resistances for heat spreading. However, these resistances are much lower than for the plane $\mathrm{Cu}$ spreaders of almost the same thickness. The plane $\mathrm{Cu}$ spreaders remove much less thermal powers and have smaller footprint areas than the MPC spreaders (Fig. 9a). $R_{T I M}$ is constant $\left(0.19^{\circ} \mathrm{C} / \mathrm{W}\right)$ and independent of the HFR for the underlying chip as well as the thermal power removed from the spreader surface. It depends on the surface area of the underlying chip, which in the present analysis is constant $1 \mathrm{~cm}^{2}$.

The total thermal resistances, $R_{T O T}$, of the spreaders increase as either the HFR for the Chip's CHS increases or the thickness of the $\mathrm{Cu}$ substrate in the MPC spreaders (Fig. 9b) or the plane $\mathrm{Cu}$ spreaders decreases (Fig. 9a). The highest total resistance in Fig. 9a is that of the $1.6 \mathrm{~mm}$ thick plane $\mathrm{Cu}$ spreader when $\mathrm{HFR}=6\left(0.81^{\circ} \mathrm{C} / \mathrm{W}\right)$. This resistance is $42.6 \%$ higher than that of the MPC spreader $(0.568 \mathrm{C} / \mathrm{W})$ with the same $\mathrm{Cu}$ substrate thickness of $1.6 \mathrm{~mm}$ (Fig. 9b). When HFR = 6 , increasing the thickness of the plane $\mathrm{Cu}$ spreader to $3.2 \mathrm{~mm}$ decreases its total thermal resistance to $0.677^{\circ} \mathrm{C} / \mathrm{W}$ (Fig. 9a). This 
resistance is $31.6 \%$ higher than that of the MPC (or composite) spreader $\left(0.515^{\circ} \mathrm{C} / \mathrm{W}\right)$ with the same $\mathrm{Cu}$ substrate thickness of $3.2 \mathrm{~mm}$ (Fig. $9 \mathrm{~b}$ ).
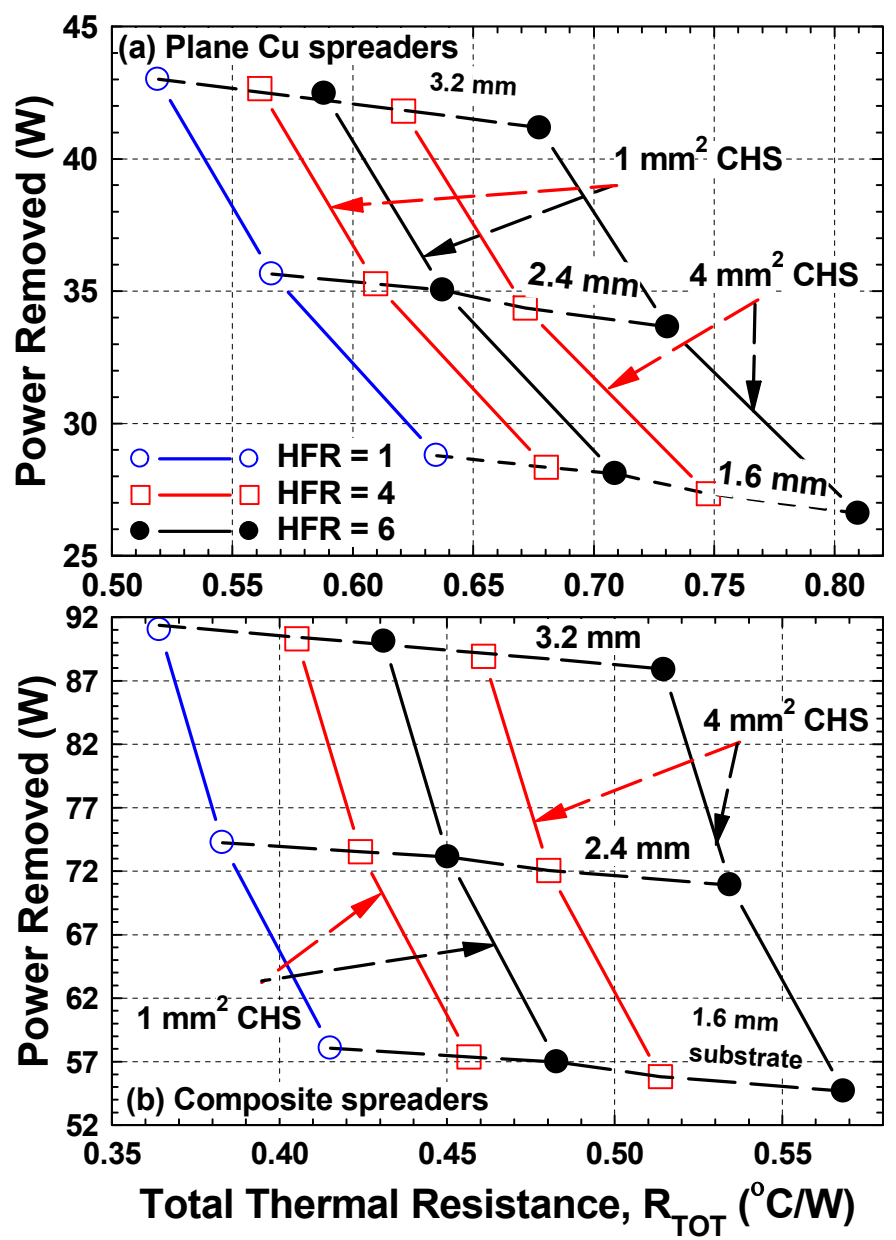

Fig. 10 Removed Thermal Power versus Total Thermal Resistance for Plane $\mathrm{Cu}$ and MPC Spreaders.

For both the plane $\mathrm{Cu}$ and MPC (or composite) spreaders, the increases in the total thermal resistance are associated with decreases in the thermal power removed and the spreaders' footprint areas (Figs. 10 and 11). For the same area and HFR of CHS of the underlying chip, the total thermal resistances of the plane $\mathrm{Cu}$ spreaders are consistently higher and the removed thermal powers are lower than those for the MPC spreaders Figs. 10a and 10b). Increasing the area and HFR of the CHS decrease the removed thermal powers and increase the spreaders' total thermal resistances (Figs. 10a and 10b). For an underlying chip with $4 \mathrm{~mm}^{2} \mathrm{CHS}$ and HFR $=6$, the thermal powers removed by the plane $\mathrm{Cu}$ and the MPC spreaders are the lowest and the corresponding total thermal resistances are the highest.

Decreasing the area or HFR of the CHS and / or increasing the thickness of the plane $\mathrm{Cu}$ spreaders or the $\mathrm{Cu}$ substrates in the MPC (or composite) spreaders, increase the thermal powers removed from the spreaders' surfaces and decrease their total thermal resistances. The highest thermal powers removed and the lowest total thermal resistances are those of the MPC spreaders when the heat dissipation by the underlying chip is uniform $(\mathrm{HFR}=1)$ and the $\mathrm{Cu}$ substrate is 3.2 $\mathrm{mm}$ thick (Fig. 10b). For this $\mathrm{Cu}$ substrate, the thermal power removed by the MPC spreader and the corresponding total thermal resistance are $87.85 \mathrm{~W}$ and $0.515^{\circ} \mathrm{C} / \mathrm{W}$, when the area and HFR of the CHS are $4 \mathrm{~mm}^{2}$ and 6 , respectively.

The thermal power removed from the surface of the MPC spreader by saturation boiling of PF-5060 dielectric liquid decreases to $54.66 \mathrm{~W}$ and the total thermal resistance increases to $0.568^{\circ} \mathrm{C} / \mathrm{W}$ when the thickness of $\mathrm{Cu}$ substrate decreases to $1.6 \mathrm{~mm}$ (Fig. 10b). By comparison, when the area and HFR of the CHS are $4 \mathrm{~mm}^{2}$ and 6 , the thermal power removed by the $1.6 \mathrm{~mm}$ thick plane $\mathrm{Cu}$ spreader is only $26.6 \mathrm{~W}$ and its total thermal resistance is as much as $0.81^{\circ} \mathrm{C} / \mathrm{W}$.
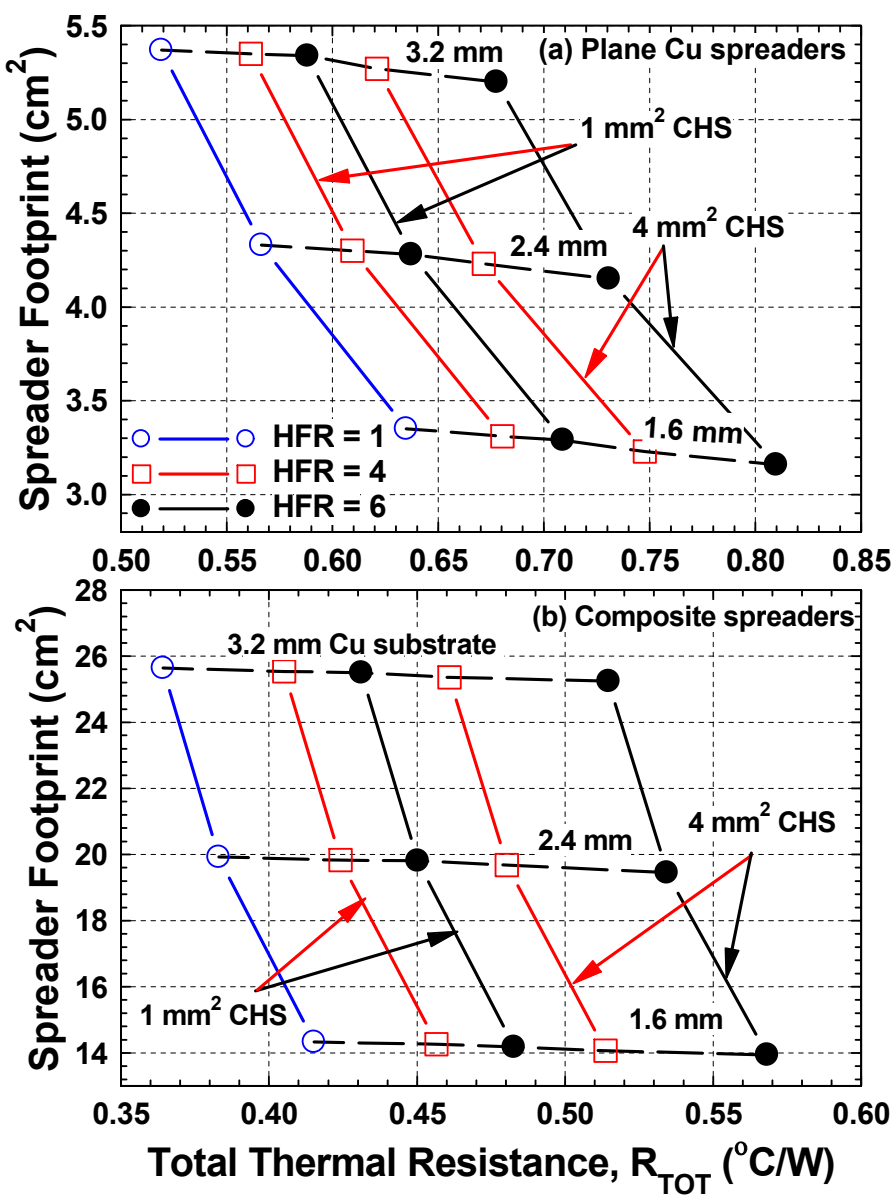

Fig. 11 Calculated footprint area versus the total thermal resistance for the plane $\mathrm{Cu}$ and MPC spreaders.

\subsection{Spreaders' Surface Areas}

The increases in the total thermal resistances of the spreaders are associated with decreases of both the thermal powers removed and the footprint areas (Figs. 10 and 11). Figures 11a and 11b plot the calculated footprint areas of the plane $\mathrm{Cu}$ and MPC (or composite) spreaders versus their total thermal resistances. While the footprint areas of the MPC spreaders are larger than those of the plane $\mathrm{Cu}$ spreaders, their total thermal resistances are lower. This is because the thermal powers removed by the MPC spreaders are markedly higher than by the plane $\mathrm{Cu}$ spreaders (Figs. 10a and 10b).

The footprint area of the MPC spreader with a $3.2 \mathrm{~mm}$ thick $\mathrm{Cu}$ substrate is $25.25 \mathrm{~cm}^{2}$, when the area and HFR of the CHS in the underlying chip are $4 \mathrm{~mm}^{2}$ and 6 , respectively (Fig. 11b). When the CHS area decreases to $1 \mathrm{~mm}^{2}$ the footprint area of this same MPC spreader increases only slightly to $25.5 \mathrm{~cm}^{2}$. However, the spreader's total thermal resistance decreases from 0.515 to $0.431^{\circ} \mathrm{C} / \mathrm{W}$ (Fig. 11b) The footprint areas of the $3.2 \mathrm{~mm}$ thick plane $\mathrm{Cu}$ spreader are 5.2 and $5.34 \mathrm{~cm}^{2}$ when HFR $=6$ and the CHS area is 1 and $4 \mathrm{~mm}^{2}$, respectively. The corresponding total thermal resistances for this spreader are 0.588 ${ }^{\circ} \mathrm{C} / \mathrm{W}$ and $0.677^{\circ} \mathrm{C} / \mathrm{W}$ (Fig. 11a), while the removed thermal powers are $42.47 \mathrm{~W}$ and $41.16 \mathrm{~W}$, respectively (Fig. 10a).

The smallest footprint areas and total thermal resistances and the largest thermal powers removed are those of the MPC (or composite) spreaders when the heat dissipated by the underlying chip is uniform (i.e., HFR $=1$ in Fig. 11b). For this condition, the MPC spreaders with $2.4 \mathrm{~mm}$ and $3.2 \mathrm{~mm}$-thick $\mathrm{Cu}$ substrates remove $74.26 \mathrm{~W}$ and $91.0 \mathrm{~W}$ and have total thermal resistances of $0.383^{\circ} \mathrm{C} / \mathrm{W}$ and $0.364^{\circ} \mathrm{C} / \mathrm{W}$, respectively (Fig. 11b). For the plane $\mathrm{Cu}$ spreaders of almost the same thicknesses, the removed thermal powers are lower, 35.65 and $43.0 \mathrm{~W}$ 
and the total thermal resistances are higher, 0.566 and $0.519^{\circ} \mathrm{C} / \mathrm{W}$, respectively (Fig. 11a), than those of the MPC spreader (Fig. 11b).

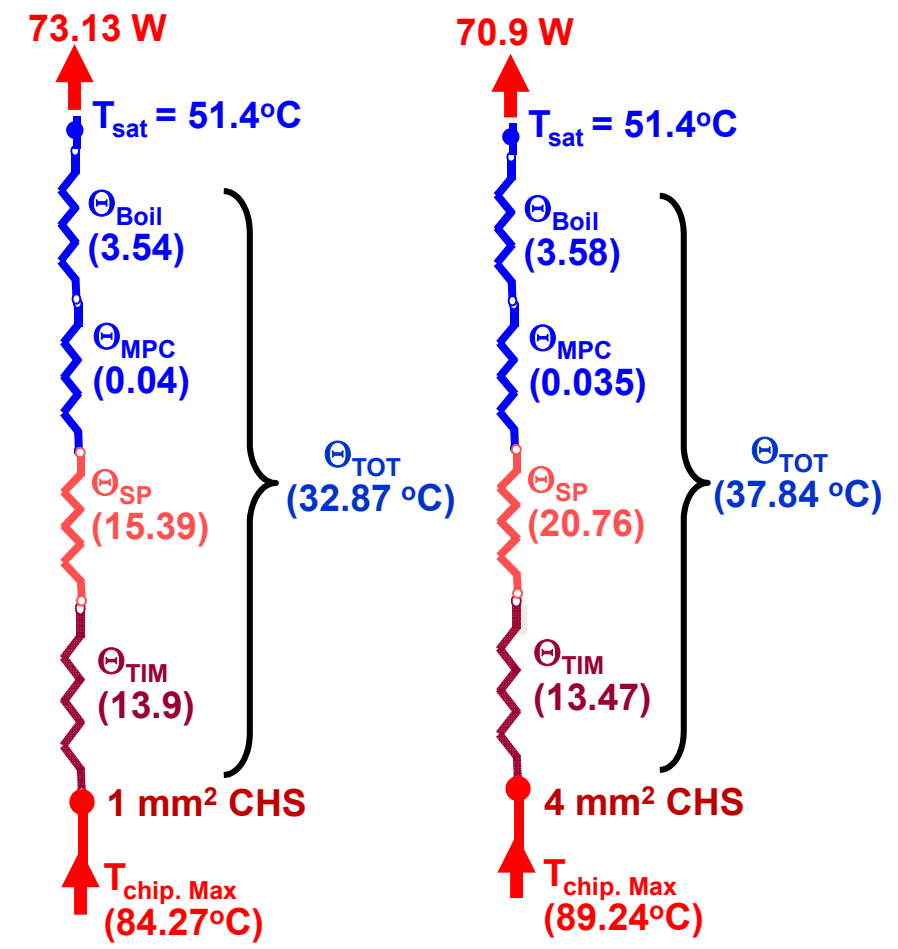

(a) MPC spreaders
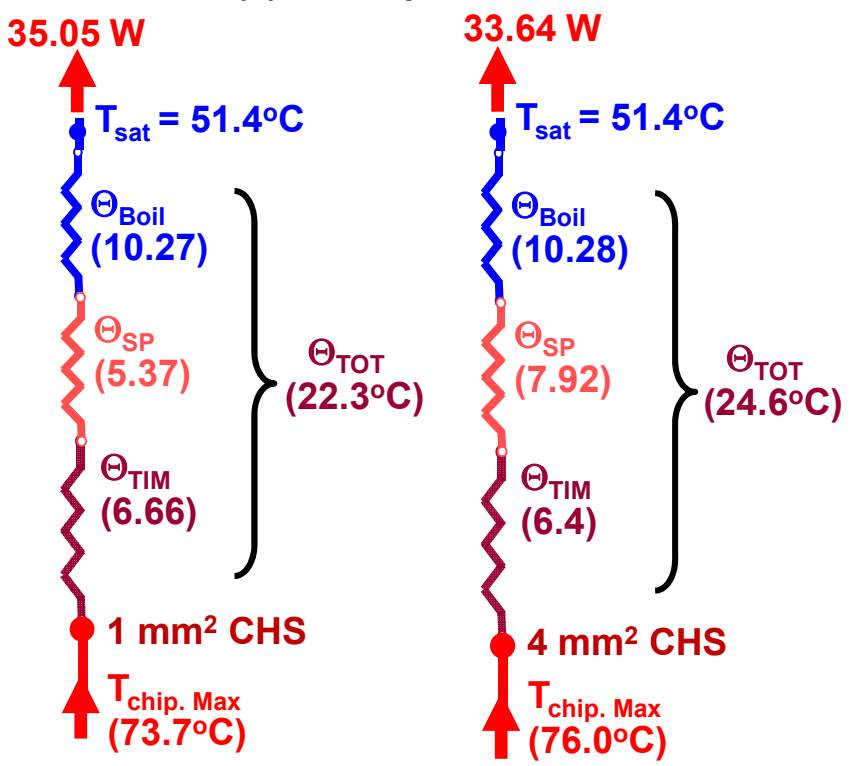

(b) Plane Cu spreaders

Fig. 12 Chip maximum surface temperatures and removed thermal powers by (a) MPC and (b) plane $\mathrm{Cu}$ spreaders [HFR $=6, t_{C u}=$ $2.4 \mathrm{~mm}, T I_{T I M}=0.19^{\circ} \mathrm{C}-\mathrm{cm}^{2} / \mathrm{W}$ and $\mathrm{CHS}=1$ and $\left.4 \mathrm{~mm}^{2}\right]$.

\subsection{Calculated Chip Surface Temperature}

This section compares the calculated contributions of the various thermal resistances to the total thermal resistances of the plane $\mathrm{Cu}$ and MPC spreaders and hence, the maximum surface temperatures of the underlying chip at the CHSs. The thickness of the $\mathrm{Cu}$ spreaders and that of the $\mathrm{Cu}$ substrate of the MPC (or composite) spreaders is the same; $2.4 \mathrm{~mm}$ (Figs. 12a and 12b). The results in these figures are for a $10 \mathrm{x}$ $10 \mathrm{~mm}$ chip with 1 and $4 \mathrm{~mm}^{2}$ CHSs and HFR $=6$. Results show that the primary contributor to the total thermal resistances of the MPC spreaders is that of heat spreading in the $\mathrm{Cu}$ substrate, $R_{s p}$, followed by
$R_{T I M}, R_{\text {boil }}$, and then $R_{M P C}$, a distance fourth (Figs. $9 \mathrm{~b}$ and $12 \mathrm{~b}$ ). By contrast, the primary contributor to the total thermal resistances of the plane $\mathrm{Cu}$ spreaders is $R_{b o i l}$, followed a distance second by $R_{T I M}$ and then $R_{s p}$ (Fig. 9 and 12a). This is because of the low nucleate boiling heat transfer coefficient of PF-5060 dielectric liquid on plane $\mathrm{Cu}$ (Fig. 2b) and the small footprint areas of the plane $\mathrm{Cu}$ spreaders.

For the underlying chip with $1 \mathrm{~mm}^{2}$ CHS, the thermal power removed from the top surface of the MPC spreader by saturation nucleate boiling of PF-5060 dielectric liquid is $73.13 \mathrm{~W}$ and the maximum surface temperature at the CHS is $84.27^{\circ} \mathrm{C}$ (Fig. 12a). This temperature reflects a total rise above the saturation temperature of $\mathrm{PF}$ 5060 dielectric liquid $\left(51.4^{\circ} \mathrm{C}\right.$ in Albuquerque, $\left.\mathrm{NM}\right), \Theta_{\mathrm{TOT}}=32.87^{\circ} \mathrm{C}$. The total thermal resistance of this spreader, $R_{T O T}=0.45^{\circ} \mathrm{C} / \mathrm{W}$, is the sum of those for heat spreading in the $\mathrm{Cu}$ substrate $\left(0.208^{\circ} \mathrm{C} / \mathrm{W}\right)$, heat conduction in TIM $\left(0.19^{\circ} \mathrm{C} / \mathrm{W}\right)$, saturation boiling on the $80-\mu \mathrm{m}$ thick MPC surface $\left(0.048^{\circ} \mathrm{C} / \mathrm{W}\right)$, and heat conduction in the MPC surface layer $\left(0.00055^{\circ} \mathrm{C} / \mathrm{W}\right)$ (Figs. $9 \mathrm{~b}$ and $\left.12 \mathrm{a}\right)$. The latter is negligibly small, contributing only $0.04^{\circ} \mathrm{C}$ to the increase in the chip maximum surface temperature. The largest contribution to the maximum temperature at the chip's CHS is that of heat spreading, $\Theta_{s p}=15.39^{\circ} \mathrm{C}$, in the $2.4 \mathrm{~mm}$ thick $\mathrm{Cu}$ substrate, followed close second by that of heat conduction in TIM, $\Theta_{T I M}=13.9^{\circ} \mathrm{C}$, then saturation boiling at the spreader's top surface, $\Theta_{\text {Boil }}=3.54^{\circ} \mathrm{C}$ (Fig. 12a).

Figure 12a also shows the results for the same MPC spreader, but chip's CHS area of $4 \mathrm{~mm}^{2}$. With this CHS area, the removed thermal power decreases to $70.9 \mathrm{~W}$, but the chip's maximum surface temperature at $\mathrm{CHS}$ increases to $89.24^{\circ} \mathrm{C}$. The contributions to this temperature due heat spreading and saturation boiling are $\Theta_{s p}=20.76^{\circ} \mathrm{C}$ and $\Theta_{\text {Boil }}=3.58^{\circ} \mathrm{C}$, while those due to heat conduction in TIM and MPC top surface layer are $\Theta_{\mathrm{TIM}}=13.47^{\circ} \mathrm{C}$ and $\Theta_{\mathrm{MPC}}=0.035^{\circ} \mathrm{C}$ (Fig. 12a). With the $4 \mathrm{~mm}^{2} \mathrm{CHS}$ area, the total thermal resistance of the MPC spreader is $0.5337^{\circ} \mathrm{C} / \mathrm{W}$ and the underling chip experiences a total temperature rise of $\Theta_{\mathrm{TOT}}=37.84^{\circ} \mathrm{C}$ above the saturation temperature of the PF-5060 liquid. The total resistance of this spreader (Fig. 9b) is the sum of those for heat spreading in the $2.4 \mathrm{~mm}$ thick $\mathrm{Cu}$ substrate $\left(0.293^{\circ} \mathrm{C} / \mathrm{W}\right)$, conduction in $\operatorname{TIM}\left(0.19^{\circ} \mathrm{C} / \mathrm{W}\right)$, saturation boiling at the spreader's MPC surface $\left(0.05^{\circ} \mathrm{C} / \mathrm{W}\right)$ and heat conduction in the MPC surface layer $\left(0.0005^{\circ} \mathrm{C} / \mathrm{W}\right)$. In Fig. $12 \mathrm{a}$, the heat flux at the $1 \mathrm{~mm}^{2}$ and $4 \mathrm{~mm}^{2} \mathrm{CHS}$ of the underlying chip is $\sim 417.9 \mathrm{~W} / \mathrm{cm}^{2}$ and $354.5 \mathrm{~W} / \mathrm{cm}^{2}$, respectively.

With plane $\mathrm{Cu}$ spreader of the same thickness as the $\mathrm{Cu}$ substrates of the MPC spreader $(2.4 \mathrm{~mm})$, the total thermal powers removed for the underlying chip with 1 and $4 \mathrm{~mm}^{2}$ CHSs and HFR $=6$ are only 35.05 and $33.64 \mathrm{~W}$ (Fig. 12b). The corresponding chip maximum surface temperatures are $73.7^{\circ} \mathrm{C}$ and $76.0^{\circ} \mathrm{C}$, respectively. For the chip with $1 \mathrm{~mm}^{2} \mathrm{CHS}$, the total thermal resistance of the $2.4 \mathrm{~mm}$ thick plane $\mathrm{Cu}$ spreader is $0.636^{\circ} \mathrm{C} / \mathrm{W}$ and $0.731^{\circ} \mathrm{C} / \mathrm{W}$ when the chip has a larger CHS of $4 \mathrm{~mm}^{2}$ (Fig. 9a). These resistances are much higher than those of the MPC spreaders of almost the same thicknesses and which remove more than twice the thermal powers of the plane $\mathrm{Cu}$ spreaders.

Unlike for the MPC spreaders, the primary contributor to the total thermal resistances of the plane $\mathrm{Cu}$ spreaders in Fig. $12 \mathrm{~b}$ is that of saturation boiling at the top $\mathrm{Cu}$ surface, $R_{\text {Boill, followed by heat }}$ conduction in the TIM, $R_{T I M}$, or heat spreading, $R_{s p}$ (Fig. 9a). For the 2.4 $\mathrm{mm}$ thick plane $\mathrm{Cu}$ spreader, when the CHS area in the $10 \times 10 \mathrm{~mm}$ underlying chip is $1 \mathrm{~mm}^{2}$ (Fig. $12 \mathrm{~b}$ ), $R_{\text {Boil }}=0.293^{\circ} \mathrm{C} / \mathrm{W}, R_{T I M}=$ $0.19^{\circ} \mathrm{C} / \mathrm{W}$ and $R_{s p}=0.153^{\circ} \mathrm{C} / \mathrm{W}$ (Fig. 9a). The total contribution to the chip maximum surface temperature $\left(73.7^{\circ} \mathrm{C}\right)$ is the sum of those due saturation boiling, $\Theta_{\text {Boil }}=10.27^{\circ} \mathrm{C}$, heat conduction in TIM, $\Theta_{T I M}=$ $6.66^{\circ} \mathrm{C}$ and heat spreading, $\Theta_{s p}=5.37^{\circ} \mathrm{C}$ (Fig. 12b). Increasing the Chip's CHS area to $4 \mathrm{~mm}^{2}$ increases $R_{\text {Boil }}$ to $0.304^{\circ} \mathrm{C} / \mathrm{W}$ and $R_{\text {asp }}$ to $0.3056{ }^{\circ} \mathrm{C} / \mathrm{W}$, but $R_{T I M}$ is unchanged at $0.19^{\circ} \mathrm{C} / \mathrm{W}$ (Fig. 9a). Also, the chip maximum surface temperature at CHS increases to $76^{\circ} \mathrm{C}$, which reflects the increase in the thermal resistance due to heat spreading, $\Theta_{s p}$ $=7.92^{\circ} \mathrm{C}$, while the thermal resistances due saturation boiling of PF5060 dielectric liquid at the plane $\mathrm{Cu}$ spreader surface, $\Theta_{\text {Boil }}=10.28^{\circ} \mathrm{C}$ 
and heat conduction in TIM, $\Theta_{T I M}=6.4^{\circ} \mathrm{C}$ change only slightly (Fig. 12b). In this figure, the local heat flux at the 1 and $4 \mathrm{~mm}^{2} \mathrm{CHS}$ in the underlying chip cooled with the $2.4 \mathrm{~mm}$ thick plane $\mathrm{Cu}$ spreader is 200.3 and $168.2 \mathrm{~W} / \mathrm{cm}^{2}$. In actual applications, the chip maximum surface temperatures could be lower and the removed thermal powers could be higher than those calculated in the present analyses. This is because the analyses did not account for the heat removed from the sides and bottom surface of the spreaders, likely by forced air convection (Fig. 3).
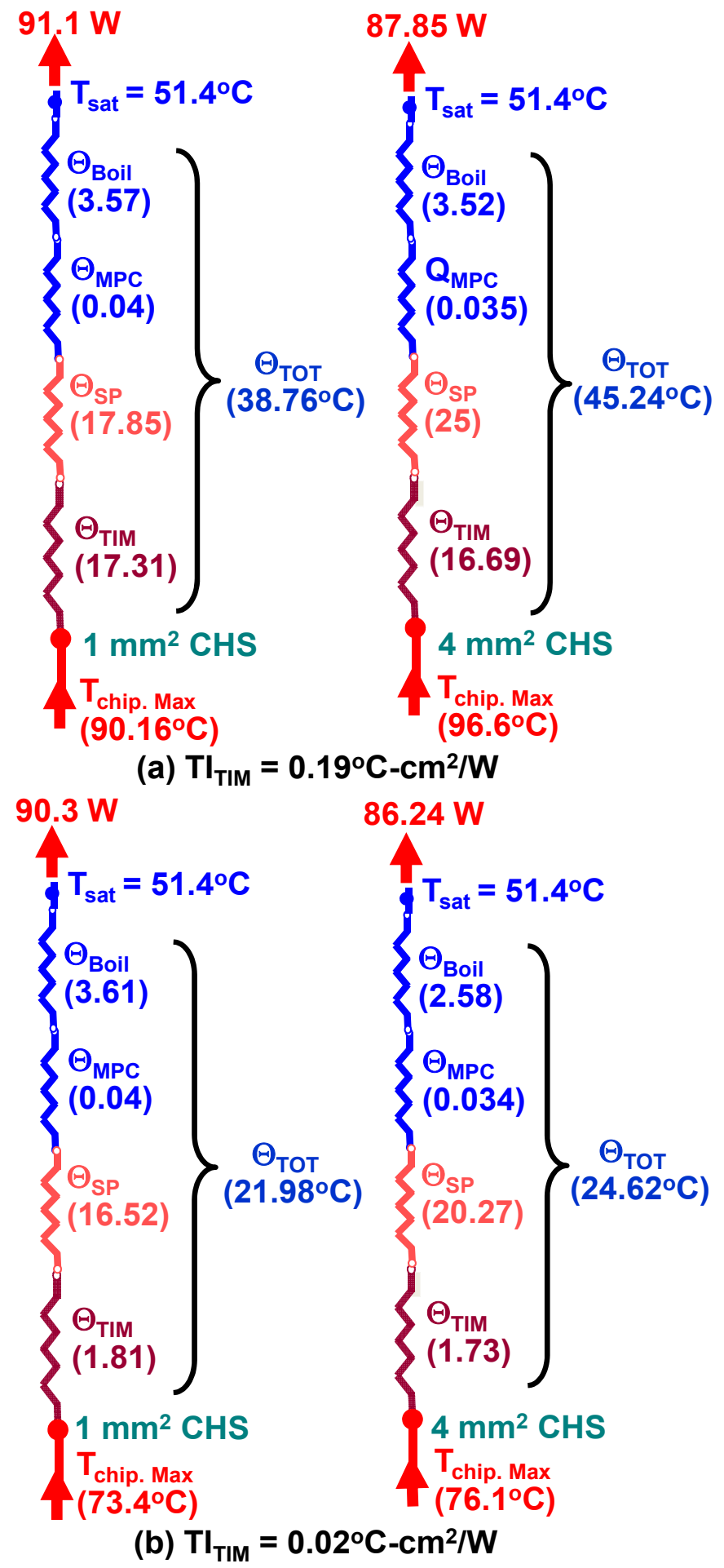

Fig. 13 Effect of $\mathrm{TI}_{\mathrm{TIM}}$ on chip maximum surface temperature and removed thermal power by MPC spreaders; (a) $\mathrm{TI}_{\mathrm{TIM}}=0.19^{\circ} \mathrm{C}$ - $\mathrm{cm}^{2} / \mathrm{W}$ and (b) $\mathrm{TI}_{\mathrm{TIM}}=0.02^{\circ} \mathrm{C}-\mathrm{cm}^{2} / \mathrm{W}\left[\mathrm{HFR}=6, \mathrm{t}_{\mathrm{Cu}}=3.2 \mathrm{~mm}\right.$, and $\mathrm{CHS}=1$ and $4 \mathrm{~mm}^{2}$ ].

The saturation temperature of PF-5060 dielectric liquid in Figs. $12 \mathrm{a}$ and $12 \mathrm{~b}\left(51.4^{\circ} \mathrm{C}\right)$ is that in Albuquerque, $\mathrm{NM}$ at $0.085 \mathrm{MPa}(51.4$ $\left.{ }^{\circ} \mathrm{C}\right)$. It is $3.1^{\circ} \mathrm{C}$ lower than at sea level or an ambient pressure of $\sim 0.1$ $\mathrm{MPa}$. At that pressure, the increases in the nucleate boiling heat transfer coefficients at the top surface of the MPC and plane $\mathrm{Cu}$ spreaders, compared to those in Fig. $2 \mathrm{~b}$ at $\sim 0.085 \mathrm{MPa}$, would slightly increase the thermal powers removed and chip's surface temperatures at CHSs.

As indicated earlier, the results presented in Figs. 5-12 are for a thermal impedance of the TIM between the $\mathrm{Cu}$ substrate and the underlying $10 \times 10 \mathrm{~mm}$ chip of $0.19^{\circ} \mathrm{C} / \mathrm{W}$. The next section presents the performance results for the MPC spreaders with a smaller TIM resistance of $0.02^{\circ} \mathrm{C} / \mathrm{W}$. This impedance is achievable by increasing the clamping pressure from $67 \mathrm{KPa}$ to $1.72 \mathrm{MPa}$ (Table 1).

\subsection{Effect of Decreasing TIM Resistance}

Performance results of the MPC spreaders with a $3.2 \mathrm{~mm}$ thick $\mathrm{Cu}$ substrate are presented for the underling chip with 1 and $4 \mathrm{~mm}^{2} \mathrm{CHS}$ and TIM impedance of $0.19^{\circ} \mathrm{C}-\mathrm{cm}^{2} / \mathrm{W}$ (Fig. 13a) and $0.02^{\circ} \mathrm{C}-\mathrm{cm}^{2} / \mathrm{W}$ (Fig. 13b). Comparing the results for the MPC spreaders in Figs. 12a and $13 \mathrm{a}$, with the same $\mathrm{TI}_{\mathrm{TIM}}$, clearly show that increasing the thickness of the $\mathrm{Cu}$ substrate from 2.4 to $3.2 \mathrm{~mm}$ increases the thermal power removed by $24.6 \%$ and $23.9 \%$ and the corresponding chip maximum surface temperature at the $1 \mathrm{~mm}^{2}$ and $4 \mathrm{~mm}^{2}$ CHS by only $\sim 7 \%$ and $8.25 \%$ to $90.16^{\circ} \mathrm{C}$ and $96.6^{\circ} \mathrm{C}$, respectively (Fig. 13a). The largest contributor to the chip maximum temperature at CHS is heat spreading in the $\mathrm{Cu}$ substrate, followed by heat conduction in TIM, and saturation boiling at spreader surface.
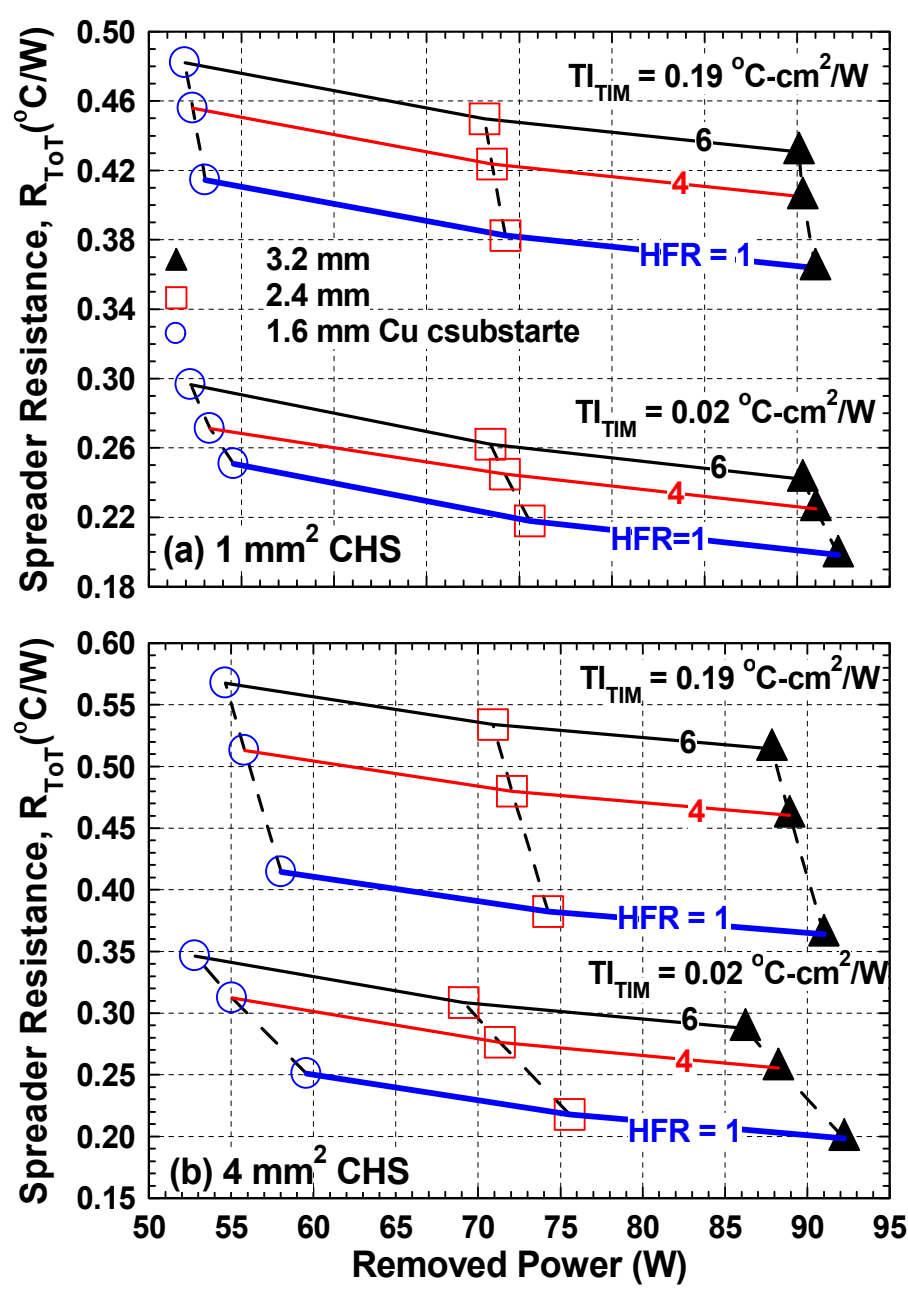
Fig. 14 Effect of $\mathrm{TI}_{\mathrm{TIM}}$ and Chip's CHS area and HFR on MPC spreaders' total thermal resistances and removed powers.

Decreasing the $\mathrm{TI}_{\mathrm{TIM}}$ between the $\mathrm{Cu}$ substrate and the underlying chip markedly decreases the chip's maximum temperatures at CHSs and only slightly the thermal powers removed by the MPC spreaders with the same $\mathrm{Cu}$ substrate thickness of $3.2 \mathrm{~mm}$, but for different areas of the CHS in the underlying chip (Figs. 13a and 13b). Fig. 13a is for $\mathrm{TI}_{\mathrm{TIM}}=0.19^{\circ} \mathrm{C}-\mathrm{cm}^{2} / \mathrm{W}$ and Fig. $13 \mathrm{~b}$ is for $\mathrm{TI}_{\mathrm{TIM}}=0.02^{\circ} \mathrm{C}-\mathrm{cm}^{2} / \mathrm{W}$. Figure 13b shows that for underlying chips with 1 and $4 \mathrm{~mm}^{2} \mathrm{CHS}$, the thermal powers removed by the MPC spreaders are $90.3 \mathrm{~W}$ and 86.24 $\mathrm{W}$, compared to $91.1 \mathrm{~W}$ and $87.85 \mathrm{~W}$ in Fig. 13a. The corresponding chip's maximum surface temperatures at CHSs of $73.4^{\circ} \mathrm{C}$ and $76.1^{\circ} \mathrm{C}$ (Fig. 13b) are significantly lower than those of $90.16^{\circ} \mathrm{C}$ and $96.6^{\circ} \mathrm{C}$ in Fig. 13a. The chip's maximum surface temperatures at CHSs in Fig. $13 \mathrm{~b}$ are much lower than those recommended by the chip manufactures $\left(\leq 85-125^{\circ} \mathrm{C}\right.$, depending on application [1]). The following subsections present additional performance results of the MPC spreaders with smaller $\mathrm{TI}_{\mathrm{TIM}}$ of $0.02^{\circ} \mathrm{C}-\mathrm{cm}^{2} / \mathrm{W}$ (Figs. 14 - 17).

\subsection{Spreader Total Thermal Resistance and Footprint area}

Results in Figs. 14a and 14b show that decreasing $\mathrm{TI}_{\mathrm{TIM}}$ from $0.19^{\circ} \mathrm{C}-\mathrm{cm}^{2} / \mathrm{W}$ to $0.02^{\circ} \mathrm{C}-\mathrm{cm}^{2} / \mathrm{W}$ decreases the total resistance of the MPC spreaders by $\sim 38-44 \%$, depending on the area and HFR for the CHS in the underling chip; it only slightly decreases the removed thermal powers by the MPC (or composite) spreaders. Results also show that increasing the chip's CHS area from $1 \mathrm{~mm}^{2}$ (Fig.14a) to 4 $\mathrm{mm}^{2}$ (Fig. 14b) decreases the total thermal resistances of the MPC spreaders, and slightly increases the removed thermal powers. The calculated changes, however, depend on the value of HFR at CHS. The performance results of MPC spreaders for the chip with CHSs $(\mathrm{HFR}=$ 2 - 6) are compared to those for the chip without CHSs (HFR $=1$ ).
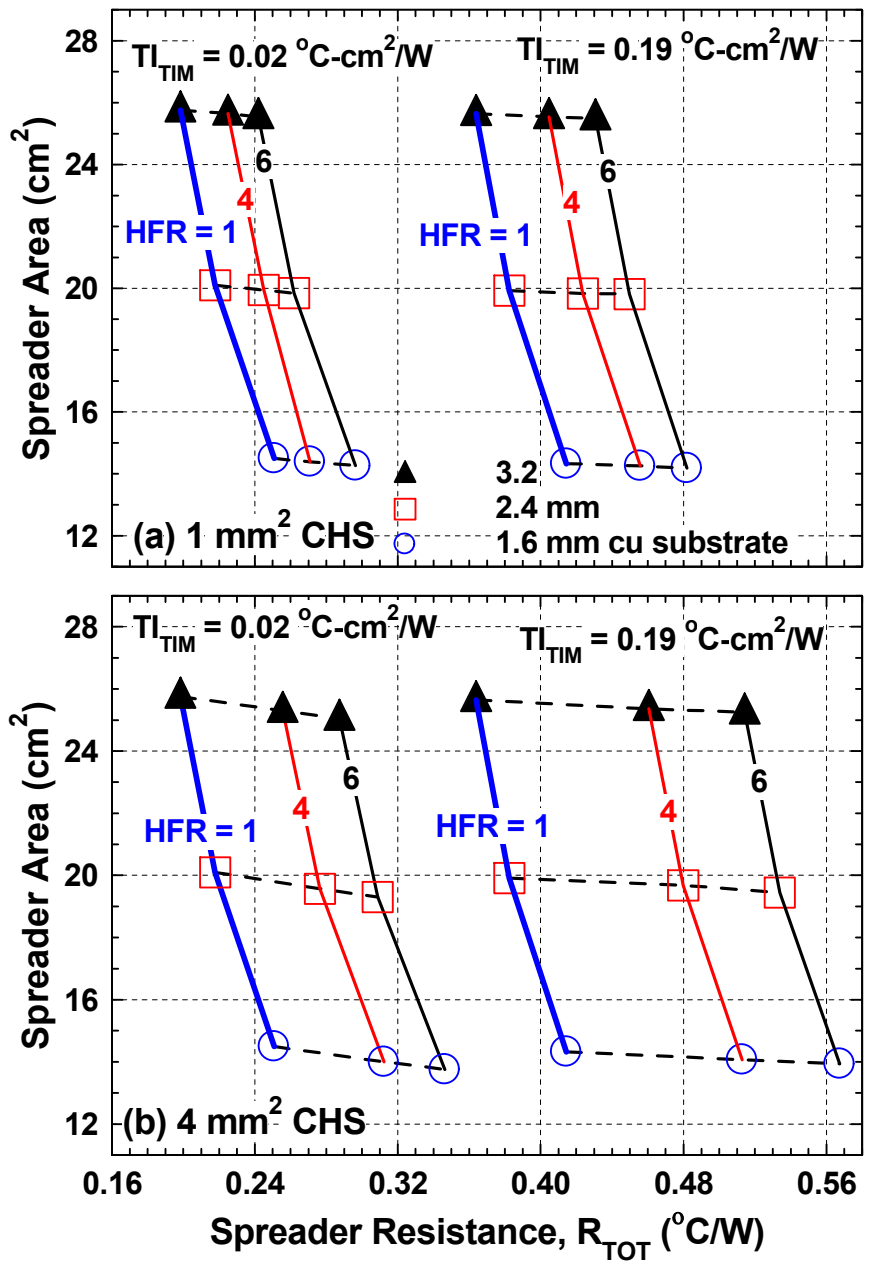

Fig. 15 Effects of $\mathrm{TI}_{\mathrm{TIM}}$ and chip's CHS's area and HFR on footprint area of MPC spreaders.

With uniform heat dissipation by the underling chip (or HFR $=1$ ), the MPC spreaders have the lowest total thermal resistances, $\mathrm{R}_{\mathrm{TOT}}$, and remove the highest thermal powers, $Q$. Increasing HFR at CHSs to 2 6 increases both $\mathrm{R}_{\text {TOT }}$ and the removed thermal powers for the MPC spreaders. The effect of increasing HFR at the chip's CHS is more pronounced for the larger CHS area of $4 \mathrm{~mm}^{2}$ (Fig. 14b). Increasing the thickness of the $\mathrm{Cu}$ substrates in the MPC spreaders decreases their total resistances because of the increase in the removed thermal powers and the decrease in the thermal resistances for heat conduction in TIM and heat spreading in the $\mathrm{Cu}$ substrate (Figs. 14a and 14b).

The removed thermal powers by the MPC spreaders increase and $\mathrm{R}_{\text {TOT }}$ decrease as $\mathrm{TI}_{\mathrm{TIM}}$ and or the thickness of the $\mathrm{Cu}$ substrate increases, and the area and /or the HFR of the CHS decreases (Figs 14a and 14b). The increases in $\mathrm{R}_{\text {ТОт }}$ depend on the footprint areas of the MPC spreaders. Figs. $15 \mathrm{a}$ and $15 \mathrm{~b}$ show that for the same CHS area in the underlying chip, $\mathrm{R}_{\mathrm{TOT}}$ of the MPC spreader increases, while its footprint area decreases as the thickness of the $\mathrm{Cu}$ substrate increases. Decreasing $\mathrm{TI}_{\mathrm{TIM}}$ markedly decreases $\mathrm{R}_{\mathrm{TOT}}$, but only slightly increases the footprint area of MPC spreader. Decreasing the HFR at the chip CHS also decreases $\mathrm{R}_{\text {TOT }}$ and increases the footprint area of the MPC spreader; these effects, however, are more pronounced for the underlying chip with the large CHS area of $4 \mathrm{~mm}^{2}$ (Fig. 15b).
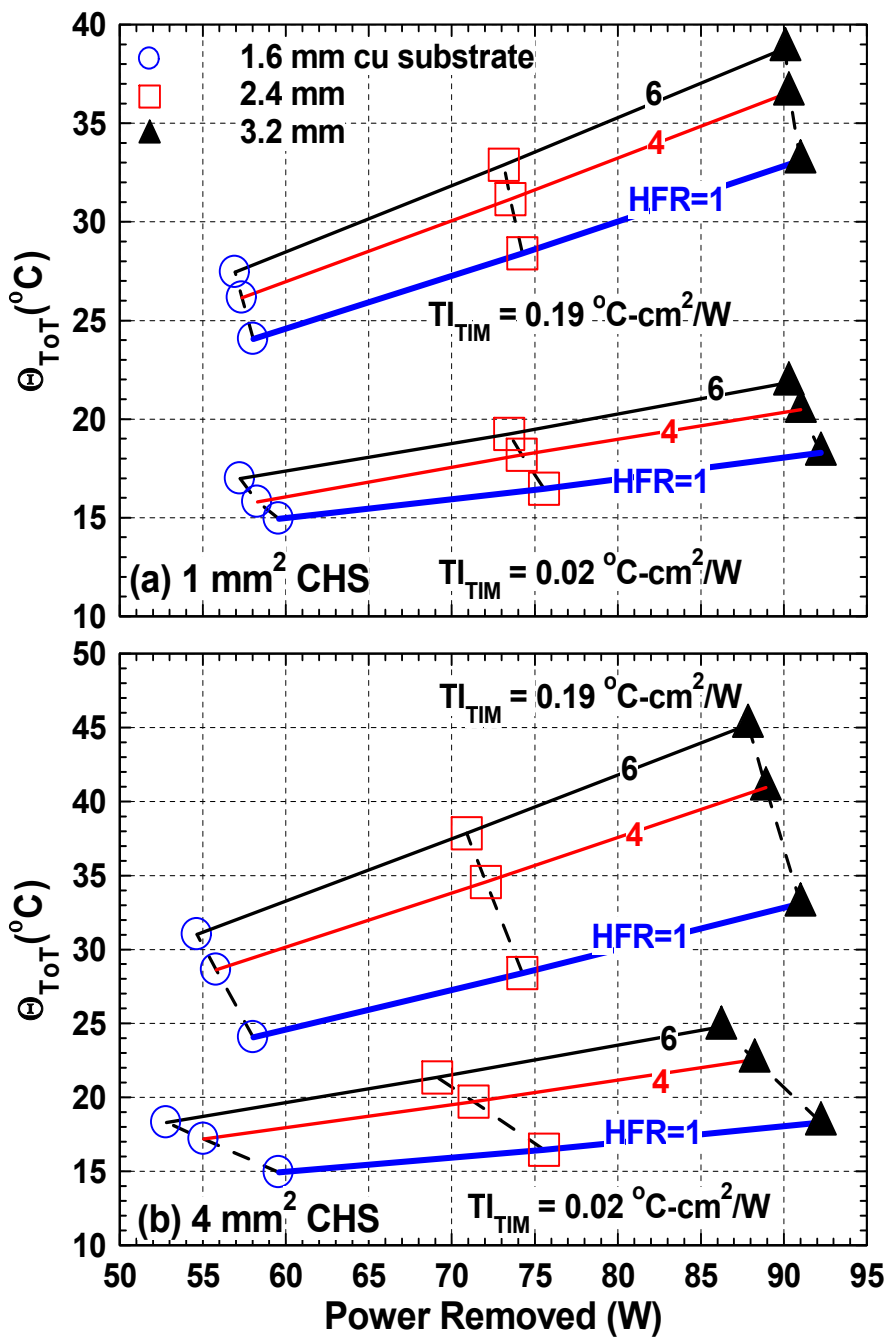

Fig. 16 Effects of the $\mathrm{TI}_{\mathrm{TIM}}$ and CHS's area and HFR on the rise in surface temperature of underlying chip. 


\subsection{Total Rise in Chip Maximum Temperature}

Figures $16 \mathrm{a}$ and $16 \mathrm{~b}$ plot the calculated total rise in the chip maximum surface temperature at CHSs, $\Theta_{\mathrm{TOT}}$, above that of saturation boiling of PF-5060 at the MPC top surface of the spreaders (Figs. 12 and 13). This temperature rise is the sum of those due to nucleate boiling, heat conduction in MPC surface layer and the TIM, and heat spreading in the $\mathrm{Cu}$ substrate. The values of $\Theta_{\text {TOT }}$ for the MPC spreaders correlate directly with the removed thermal powers and decrease as the area and HFR of the CHS in underlying chip and/or the thickness of the $\mathrm{Cu}$ substrate decrease (Figs. 16a and 16b). Decreasing the $\mathrm{Cu}$ substrate thickness decreases the temperature rise due heat spreading (Fig. 9b), decreasing both $\Theta_{\text {TOT }}$ and the removed thermal powers by the MPC spreaders (Figs.12a, 13a and 16). For the same $\mathrm{Cu}$ substrate thickness and HFR and area of CHS, decreasing $\mathrm{TI}_{\mathrm{TIM}}$ from $0.19^{\circ} \mathrm{C}-\mathrm{cm}^{2} / \mathrm{W}$ to $0.02^{\circ} \mathrm{C}-\mathrm{cm}^{2} / \mathrm{W}$ markedly decreases $\Theta_{\text {TOT }}$ for the MPC spreaders and hence, the chip's maximum surface temperature at CHS (Figs. 16 and 17).
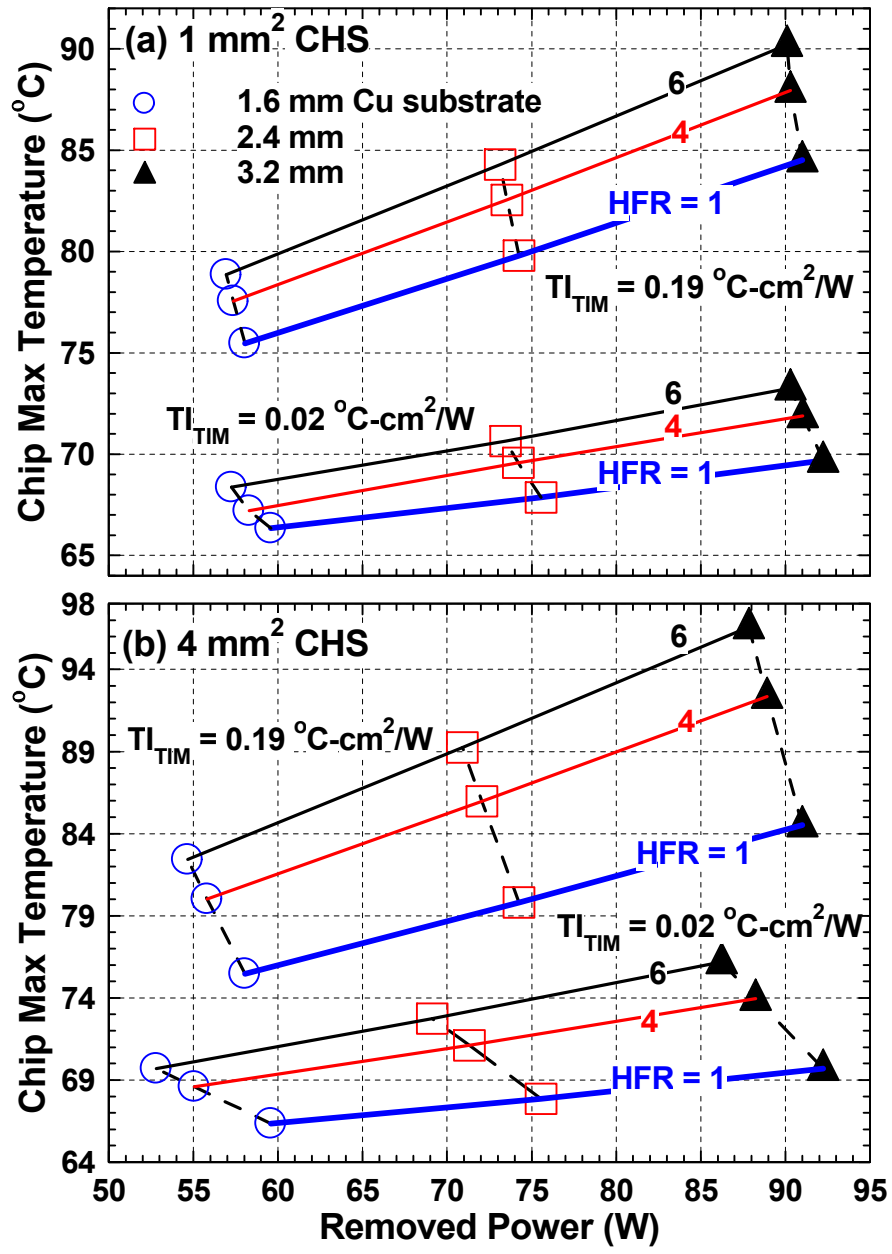

Fig. 17 Effects of $\mathrm{TI}_{\mathrm{TIM}}$ and the chip's CHS area and HFR on of the chip maximum surface temperature.

\subsection{Chip Maximum Surface Temperature}

The results in Figs. 17a and $17 \mathrm{~b}$ are of the maximum surface temperature at CHS of the underlying $10 \times 10 \mathrm{~mm}$ chip with MPC spreaders cooled by saturation nucleate boiling of PF-5060 dielectric liquid. This temperature at the chip's CHS directly correlates with the removed thermal power by the MPC spreader. It is highest for the spreader with $3.2 \mathrm{~mm}$ thick $\mathrm{Cu}$ substrate and CHS area and HFR of 4 $\mathrm{mm}^{2}$ and 6, respectively (Fig. 17b), and lowest for the chip with a uniform heat dissipation $(\mathrm{HFR}=1)$.

Decreasing the $\mathrm{TI}_{\mathrm{TIM}}$ from $0.19^{\circ} \mathrm{C}-\mathrm{cm}^{2} / \mathrm{W}$ to $0.02^{\circ} \mathrm{C}-\mathrm{cm}^{2} / \mathrm{W}$ decreases the chip's maximum surface temperature at CHS by as much as $\sim 10.5-21^{\circ} \mathrm{C}$, depending on the thickness of the $\mathrm{Cu}$ substrate and the area and HFR of the CHS (Figs. 17a and 17b). For the chip with 4 $\mathrm{mm}^{2} \mathrm{CHS}$, the maximum surface temperature at the CHS is a few degrees higher and the removed thermal power by the MPC spreader is a few watts lower than for the chip with $1 \mathrm{~mm}^{2} \mathrm{CHS}$.

When $\mathrm{TI}_{\mathrm{TIM}}=0.02^{\circ} \mathrm{C}-\mathrm{cm}^{2} / \mathrm{W}$ and $\mathrm{Cu}$ substrate thickness is $3.2 \mathrm{~mm}$, the calculated chip maximum surface temperatures are $\leq 76^{\circ} \mathrm{C}$ and the removed thermal powers by MPC spreaders are $>86 \overline{\mathrm{W}}$, regardless of the area and HFR for CHSs in the underling chip (Figs. 17a and 17b).

Figures $18 \mathrm{a}$ and $18 \mathrm{~b}$ present cross-sectional views of the MPC spreader and the underlying chip, which show the temperature contours in the $3.2 \mathrm{~mm}$ thick $\mathrm{Cu}$ substrate and the underlying chip with $4 \mathrm{~mm}^{2}$ and HFR of 6 for the CHS. The results in Fig. 18a are for $\mathrm{TI}_{\mathrm{TIM}}=$ $0.02^{\circ} \mathrm{C}-\mathrm{cm}^{2} / \mathrm{W}$ and those in Fig. $18 \mathrm{~b}$ are for $\mathrm{TI}_{\mathrm{TIM}}=0.19^{\circ} \mathrm{C}-\mathrm{cm}^{2} / \mathrm{W}$. Not that the chip maximum surface temperature at CHS in Fig. 18a and 19a is $>20.46^{\circ} \mathrm{C}$ lower that in Figs. $18 \mathrm{~b}$ and $19 \mathrm{~b}$, but also the removed thermal power from the top surface of the MPC speeder is also lower (Fig. 13). Figures 19a and 19b show plane view of the calculated temperature contours at the top surface of the underling $10 \times 10 \mathrm{~mm}$ chip with $4 \mathrm{~mm}^{2}$ and HFR $=6$ for the CHS. The dotted squares at the center of the images in Figs. 19a and 19b are of the $2 \mathrm{~mm} \times 2 \mathrm{~mm}$ CHS.

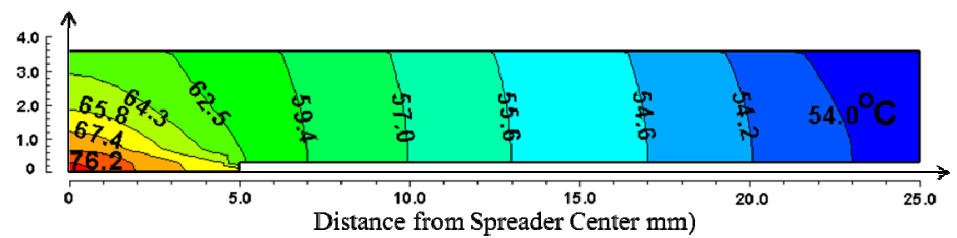

(a) $\mathrm{TI}_{\mathrm{TIN}}=0.02^{\circ} \mathrm{C}-\mathrm{cm}^{2} / \mathrm{W}, \mathrm{t}_{\mathrm{Cu}}=3.2 \mathrm{~mm}$, and $\mathrm{HFR}=6$

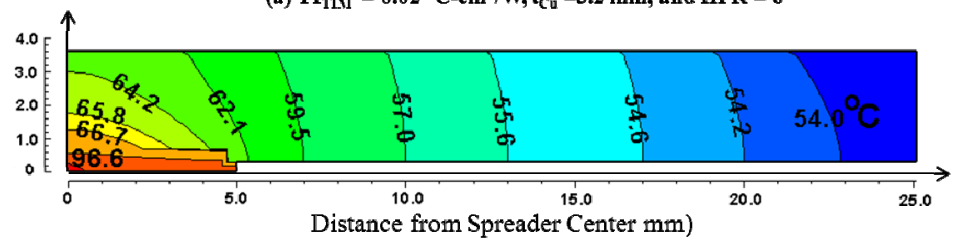

(b) $\mathrm{TI}_{\mathrm{IIII}}=0.19^{\circ} \mathrm{C}-\mathrm{cm}^{2} / \mathrm{W}, \mathrm{t}_{\mathrm{Cu}}=3.2 \mathrm{~mm}$, and $\mathrm{HFR}=6$

Fig. 18 Effect of TIM impedance on calculated temperature contours at mid-section of MPC spreaders for cooling $10 \times 10 \mathrm{~mm}$ underlying chip with $4 \mathrm{~mm}^{2} \mathrm{CHS}$.

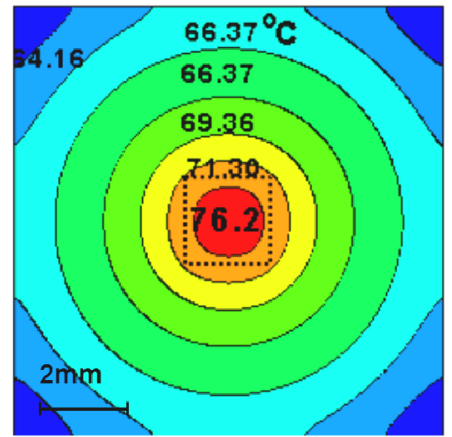

(a) $\mathrm{TI}_{\mathrm{IDI}}=0.02{ }^{\circ} \mathrm{C}-\mathrm{cm}^{2} / \mathrm{W}, \mathrm{t}_{\mathrm{Cu}}=3.2 \mathrm{~mm}$, and $\mathrm{HFR}=6$

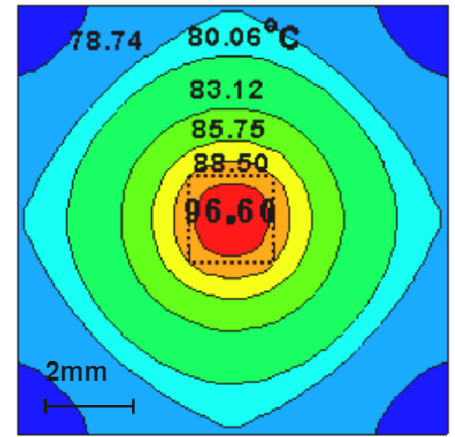

(b) $\mathrm{TI}_{\mathrm{TIM}}=0.19^{\circ} \mathrm{C}-\mathrm{cm}^{2} / \mathrm{W}, \mathrm{t}_{\mathrm{Cu}}=3.2 \mathrm{~mm}$ and $\mathrm{HFR}=6$
Fig. 19 Calculated temperature contours at top surface of $10 \times 10 \mathrm{~mm}$ chip with $4 \mathrm{~mm}^{2} \mathrm{CHS}$ and cooled using MPC spreader.

\section{SUMMARY AND CONCLUSIONS}

Numerical thermal analyses are performed to investigate the potential of $\mathrm{Cu}$ spreaders with MPC surface for immersion cooling of a $10 \times 10 \mathrm{~mm}$ underlying computer chip with a center hot spot and 
removing $>85 \mathrm{~W}$ at junctions' temperatures $<100^{\circ} \mathrm{C}$. These spreaders comprise a $1.6-3.2 \mathrm{~mm}$ thick $\mathrm{Cu}$ substrate and $80-\mu \mathrm{m}$ thick MPC surface cooled by saturation nucleate boiling of PF-5060 dielectric liquid. These spreaders take advantage of the enhancement in nucleate boiling of PF-5060 dielectric liquid on the $80-\mu \mathrm{m}$ thick MPC surface layer and the good heat spreading in the $\mathrm{Cu}$ substrate. The MPC surface layer could easily be deposited onto $\mathrm{Cu}$ substrate using conventional electrochemical deposition processes.

The performed numerical analyses investigated the effects of the local heat flux at the chip's 1 and $4 \mathrm{~mm}^{2} \mathrm{CHS}$ and the impedance of the thermal interface material (TIM), between the $\mathrm{Cu}$ substrate and underlying chip, on the spreaders' total thermal resistance and thermal power removed as well as the Chip's maximum temperature at CHS. The analyses varied the heat flux ratio at the CHSs (HFR) from 2 to 6 times that of the chip's surface average outside the hot spot. The values of the impedance of the TIM material between the $\mathrm{Cu}$ substrate and the underlying chip are 0.19 and to $0.02^{\circ} \mathrm{C}--\mathrm{cm}^{2} / \mathrm{W}$.

Calculated are the spreaders' total thermal resistances, footprint areas and thermal powers removed. Also calculated are the individual thermal resistances for saturation boiling at the spreaders' surface, heat conduction in the MPC surface layer, heat spreading in $\mathrm{Cu}$ substrate, and heat conduction in TIM. In addition, the spatial temperature distributions at the chip and spreaders' surfaces and the chip's maximum surface temperature at CHS are calculated and compared. The performance results of the MPC spreaders are compared to those of plane $\mathrm{Cu}$ spreaders of the same thickness as the $\mathrm{Cu}$ substrates in the MPC spreaders and to those with no CHS in the underlying chip (HFR $=1$ or uniform heat dissipation).

The results clearly demonstrate the effectiveness of the MPC spreaders for immersion nucleate boiling cooling of underlying $10 \times 10$ mm chip with CHS areas of 1 and $4 \mathrm{~mm}^{2}$, and HFR of as much as 6 at CHSs. Increasing the CHS area and HFR decrease the removed thermal powers and increase the total thermal resistances of the MPC spreaders. Increasing the $\mathrm{Cu}$ substrate thickness increases the thermal powers removed and decreases the total thermal resistances of the MPC spreaders. The removed thermal powers by these spreaders are highest and the total thermal resistances are lowest when the heat dissipation by the $10 \times 10 \mathrm{~mm}$ underlying chip is uniform (HFR =1). When the CHS area and HFR are $4 \mathrm{~mm}^{2}$ and 6 , the thermal power removed by the MPC spreader with $3.2 \mathrm{~mm}$ thick $\mathrm{Cu}$ substrate is $87.85 \mathrm{~W}$ and the corresponding total thermal resistance is $0.515^{\circ} \mathrm{C} / \mathrm{W}$.

When the CHS area of the underlying chip decreases to $1 \mathrm{~mm}^{2}$, while keeping the HFR at 6 , the MPC spreader with $3.2 \mathrm{~mm}$ thick $\mathrm{Cu}$ substrate removes $91.1 \mathrm{~W}$ and has a total thermal resistance of $0.425^{\circ} \mathrm{C} / \mathrm{W}$. The largest contributor to this resistance is that of heat spreading in the $\mathrm{Cu}$ substrate $\left(0.1976^{\circ} \mathrm{C} / \mathrm{W}\right)$, followed by that of heat conduction in $\mathrm{TIM}\left(0.19^{\circ} \mathrm{C} / \mathrm{W}\right)$ and saturation boiling $\left(0.039^{\circ} \mathrm{C} / \mathrm{W}\right)$. The thermal resistance of MPC layer is significantly small $\left(0.00044^{\circ} \mathrm{C} / \mathrm{W}\right)$.

When HFR $=6$, decreasing the thickness of the $\mathrm{Cu}$ substrate in the MPC spreader to 2.4 decreases the thermal power removed for the $10 \mathrm{x}$ $10 \mathrm{~mm}$ underlying chip with 1 and $4-\mathrm{mm}^{2}$ CHSs to 73.13 and $70.9 \mathrm{~W}$, respectively. The corresponding chip maximum surface temperatures at these CHSs are $84.27^{\circ} \mathrm{C}$ and $89.24^{\circ} \mathrm{C}$, respectively. In electronics cooling applications, the $\mathrm{TI}_{\mathrm{TIM}}$ of $0.02^{\circ} \mathrm{C}-\mathrm{cm}^{2} / \mathrm{W}$ would effectively decrease the chip's maximum surface temperature, while negligibly decreasing the thermal powers removed by the MPC spreaders. The performance of the plane $\mathrm{Cu}$ spreaders of the same thickness as the $\mathrm{Cu}$ substrates in the MPC spreaders is markedly inferior. The total thermal resistances of the plane $\mathrm{Cu}$ spreaders are consistently higher and the removed thermal powers are lower than those using the MPC spreaders.

The effectiveness of the MPC spreaders for immersion cooling is demonstrated in terms of increasing the removed thermal powers for the $10 \times 10 \mathrm{~mm}$ underlying Chip with CHS to in excess of $85 \mathrm{~W}$, decreasing the total thermal resistance for maintaining acceptable chip maximum surface temperatures at $\mathrm{CHS}$ of $<100^{\circ} \mathrm{C}$. The MPC spreaders mitigate the effect of the CHSs by limiting the increase in the chip's maximum surface temperature to only a few degrees, even when the HFR at the
CHSs is 6 times that of the chip's surface average outside the CHSs. It is worth noting that in immersion cooling applications, the chip's maximum surface temperature could be somewhat lower than those calculated in the present analysis, which did not take credit for the heat removal, likely by forced convection of air, from the sides and bottom surfaces of the spreaders and the die.

\section{ACKNOWLEDGEMENTS}

This research is funded by the University of New Mexico's Institute for Space and Nuclear Power Studies.

\section{NOMENCLATURE}

\begin{tabular}{ll} 
A & surface or footprint area $\left(\mathrm{cm}^{2}\right)$ \\
CHF & critical heat flux $\left(\mathrm{W} / \mathrm{cm}^{2}\right)$ or $\left(\mathrm{kW} / \mathrm{m}^{2}\right)$ \\
CHS & central hot spot \\
HFR: & heat flux ratio at CHS \\
Cu & Copper \\
h & heat transfer coefficient $\left(\mathrm{W} / \mathrm{cm}^{2} \mathrm{~K}\right)$ or $\left(\mathrm{kW} / \mathrm{m}^{2} \mathrm{~K}\right)$ \\
L & width $(\mathrm{cm})$ or $(\mathrm{mm})$ \\
MPC & micro-porous copper \\
$Q$ & thermal power removed from spreader surface $(\mathrm{W})$ or $(\mathrm{kW})$ \\
X, y, z & cartésien coordinats $($ Fig. 3$)$ \\
$R$ & thermal resistance $\left({ }^{\circ} \mathrm{C} / \mathrm{W}\right)$ \\
t & thickness $($ mm) or $(\mu \mathrm{m})$ \\
T & temperature $\left({ }^{\circ} \mathrm{C}\right)$ or $(\mathrm{K})$ \\
TI & thermal impedance $\left({ }^{\circ} \mathrm{C}-\mathrm{cm}{ }^{2} / \mathrm{W}\right)$ \\
TIM & thermal interface material \\
Greek symbols \\
$\Theta$ & temperature rise $\left({ }^{\circ} \mathrm{C}\right)$ or $(\mathrm{K})$ \\
$\rho$ & density $\left(\mathrm{kg} / \mathrm{m}^{3}\right)$ \\
$\sigma$ & surface tension $(\mathrm{N} / \mathrm{m})$ \\
Subscripts & \\
Boil & saturation nucleate boiling \\
Chip & computer chip, chip surface \\
Cu & Copper \\
$\ell$ & liquid \\
NB & nucleate boiling \\
Max & maximum \\
MNB & maximum nucleate boiling \\
MPC & micro-porous Cu \\
s & surface \\
sat & saturation \\
sp & spreader, Cu substrate \\
TIM & thermal interface material \\
TOT & total \\
$v$ & vapor \\
& \\
\hline &
\end{tabular}

\section{REFERENCES}

ITRS, International technology roadmap for semiconductors, 2009.

Lin, S.-C., and Banerjee, K., 2008, "Cool chips: opportunities and implications for power and thermal management," IEEE Transactions on Electron Devices, 55(1), 245 - 255.

http://dx.doi.org/10.1109/TED.2007.911763

Anderson, T.M., and Mudawar, I., 1989, "Microelectronic cooling by enhanced pool boiling of a dielectric fluorocarbon liquid," Journal of Heat Transfer, 111 (3), 752 - 759.

http://dx.doi.org/10.1115/1.3250747.

Liu, W., Lin, W. W., Lee, D. J. Lee and Peng, X. F., 2001, "Pool Boiling of FC-72 and HFE-7100," Journal of Heat Transfer, 123, 399 400.

http://dx.doi.org/10.1115/1.1285892. 
Honda, H. and Wei, J. J., 2003, "Advances in enhanced boiling heat transfer from electronic components," JSME International Journal Series B: Fluids and Thermal Engineering, 46, 479 - 490.

http://dx.doi.org/10.1299/jsmeb.46.479.

El-Genk, M. S., Saber, H. H., and Parker, J. L., 2007, "Efficient spreader for cooling high-power computer chips," Journal of Applied Thermal Engineering, 27 (5), 1072 - 1088.

http://dx.doi.org/10.1016/j.applthermaleng.2006.07.039.

El-Genk, M. S., and Saber, H. H., 2008, "Composite spreader for cooling computer chip with non-uniform heat dissipation," IEEE Transactions on Components and Packaging Technologies, 31 (1), 165 - 172 .

http://dx.doi.org/10.1109/TCAPT.2008.916847.

El-Genk, M. S., 2012, "Immersion Cooling Nucleate Boiling of High Power Chips," Journal of Energy Conversion and Management, 53(1), $205-218$.

http://dx.doi.org/10.1016/j.enconman.2011.08.008.

Ali, A. F., and El-Genk, M. S., 2012, "Spreaders for immersion nucleate boiling of a computer chip with a central hot spot," Journal of Energy Conversion and Management, 53(1), 259 - 267.

http://dx.doi.org/10.1016/j.enconman.2011.09.007.

El-Genk, M. S., and Bostanci, H., 2003, "Saturation boiling of HFE7100 from a copper surface, simulating a microelectronic chip," International Journal of Heat and Mass Transfer, 46, 1841-1854. http://dx.doi.org/10.1016/S0017-9310(02)00489-1.

Jung, J.-Y., and Kwak, H.-Y., 2006, "Effect of surface condition on boiling heat transfer from silicon chip with submicron-scale roughness," International Journal of Heat and Mass Transfer, 49 (2324), $4543-4551$.

http://dx.doi.org/10.1016/j.ijheatmasstransfer.2006.03.045.

Parker, J. L., and El-Genk, M. S., 2005, "Enhanced saturation and subcooled boiling of FC-72 dielectric liquid," International Journal of Heat and Mass Transfer, 48 (18), 3736 - 3752.

http://dx.doi.org/10.1016/j.ijheatmasstransfer.2005.03.011.

Rainey, K. N., and You, S. M., 2000, "Pool boiling heat transfer from plain and microporous, square pin-finned surfaces in saturated FC-72," ASME Journal of Heat Transfer, 122 (3), 509 - 516.

http://dx.doi.org/10.1115/1.1288708

Reed, S. J., and Mudawar, I., 1999, "Elimination of boiling incipience temperature drop in highly wetting fluids using spherical contact with a flat surface," International Journal of Heat and Mass Transfer, 42 (3), 2439 - 2454.

http://dx.doi.org/10.1016/S0017-9310(98)00331-7.

Chang, J. Y., and You, S. M., 1997, "Boiling heat transfer phenomena from microporous and porous surfaces in saturated FC-72," International Journal of Heat and Mass Transfer, 40 (18), 4437 - 4447. http://dx.doi.org/10.1016/S0017-9310(97)00055-0.

Launay, A. G., Fedorov, Y., Joshi, A., Cao, A., and Ajayan, P. M., 2006, "Hybrid micro-nano structured thermal interfaces for pool boiling heat transfer enhancement," Microelectronics Journal, 37 (11) (2006) $1158-1164$.

http://dx.doi.org/10.1016/j.mejo.2005.07.016.

El-Genk, M. S., and Parker, J. L., 2005, "Enhanced boiling of HFE7100 dielectric liquid on a porous graphite," Journal of Energy Conversion and Management, 46 (15), 2455 - 2481. http://dx.doi.org/10.1016/j.enconman.2004.11.012.

Ferjančič, K., Rajšelj, D., and Golobič, I., 2006, "Enhanced pool boiling CHF in FC-72 from a modulated porous layer coating," Journal of Enhanced Heat Transfer, 13(2), 175 - 184.

http://dx.doi.org/10.1615/JEnhHeatTransf.v13.i2.60.

El-Genk, M. S., and Ali, A. F., 2010, "Enhanced nucleate boiling on copper micro-porous surfaces," International Journal of Multiphase Flow, 36(10), 780 - 792.

http://dx.doi.org/10.1016/j.ijmultiphaseflow.2010.06.003.

Shin, H. C., and Liu, M. L., 2004, "Copper foam structures with highly porous nanostructural walls," Chemistry of Materials, 16(25), 5460 5464.

http://dx.doi.org/10.1021/cm048887b.

Shin, H. C., Dong, J., and Liu, M. L., 2003, "Nanoporous structure prepared by an electrochemical deposition processes," Advances in Materials, 15(19), 1610 - 1614.

http://dx.doi.org/10.1002/adma.200305160.

3M Performance fluid PF-5060, 2012.

http://multimedia.3m.com/mws/mediawebserver?mwsId=SSSSSu7zK1 fslxtUM8tZ18_Bev7qe17zHvTSevTSeSSSSSS--

$\& \mathrm{fn}=$ prodinfo_pf5060.pdf.

Thermflow ${ }^{T M}$ phase-change materials product data, 2012. http://www.hagelec.com/Phase\%20Change\%20Materials.pdf.

COMSOL MULTIPHYSICS, COMSOL 4.0a, COMSOL AB, 2010. http://www.comsol.com. 